19.94950

SANDIA REPORT

SAND92-1131 $\cdot$ UC -706

Unlimited Release

Printed December 1993

\title{
History of Sandia National Laboratories' Auxiliary Closure Mechanisms
}

John C. Weydert, Glenda M. Ponder

\section{Propared by}

Bandle National Laboratorioe

Albuquorque, Now Moxico 87185 and Livormore, Callfornia 94550

for the United 8tates Department of Energy

under Contrect DE-ACO4-94AL85000 
Issued by Sandia National Laboratories, operated for the United States Department of Energy by Sandia Corporation.

NOTICE: This report was prepared as an account of work sponsored by an agency of the United States Government. Neither the United States Government nor any agency thereof, nor any of their employees, nor any of their contractors, subcontractors, or their employees, makes any warranty, express or implied, or assumes any legal liability or responsibility for the accuracy, completeness, or usefulness of any information, apparatus, product, or process disclosed, or represents that its use would not infringe privately owned rights. Reference herein to any specific commercial product, process, or service by trade name, trademark, manufacturer, or otherwise, does not necessarily constitute or imply its endorsement, recommendation, or favoring by the United States Government, any agency thereof or any of their contractors or subcontractors. The views and opinions expressed herein do not necessarily state or reflect those of the United States Government, any agency thereof or any of their contractors.

Printed in the United States of America. This report has been reproduced directly from the best available copy.

Available to DOE and DOE contractors from

Office of Scientific and Technical Information

PO Box 62

Oak Ridge, TN 37831

Prices available from (615) 576-8401, FTS 626-8401

Available to the public from

National Technical Information Service

US Department of Commerce

5285 Port Royal Rd

Springfield, VA 22161

NTIS price codes

Printed copy: A04

Microfiche copy: A01 
SAND92-1131

Distribution

Unlimited Release

Printed December 1993

Category UC-706

\title{
History of Sandia National Laboratories' Auxiliary Closure Mechanisms
}

\author{
John C. Weydert \\ Engineering Projects and Explosives Applications \\ Sandia National Laboratories \\ Albuquerque, New Mexico 87185
}

Glenda M. Ponder

Geo-Centers, Inc.

Albuquerque, New Mexico 87106

\begin{abstract}
An essential component of a horizontal, underground nuclear test setup at the Nevada Test Site is the auxiliary closure system. The massive gates that slam shut immediately after a device has been detonated allow the prompt radiation to pass, but block debris and hot gases from continuing down the tunnel. Thus, the gates protect experiments located in the horizontal line-of-sight steel pipe. Sandia National Laboratories has been the major designer and developer of these closure systems. This report records the history of SNL's participation in and contributions to the technology of auxiliary closure systems used in horizontal tunnel tests in the underground test program.
\end{abstract}




\section{Contents}

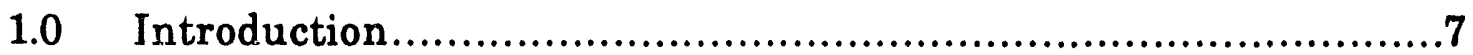

1.1 Underground Test.................................................7

1.2 Role of Closure Systems .....................................8

2.0 Closure Design Categories ..........................................9

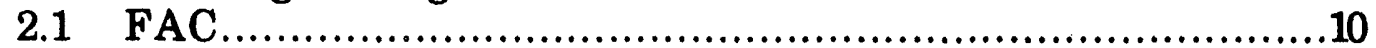

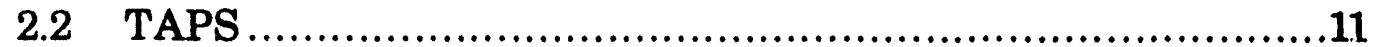

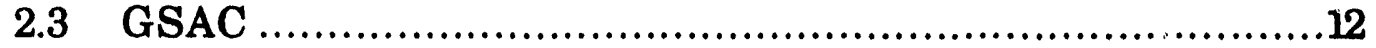

3.0 The GSAC Mechanical Closure System .................................14

3.1 Operational Theory ................................................14

3.2 Function ............................................................ 15

3.3 Performance........................................................

4.0 GSAC Design Criteria ................................................ 16

4.1 Structural ............................................................ 16

4.2 Location ............................................................... 18

4.3 Performance....................................................... 18

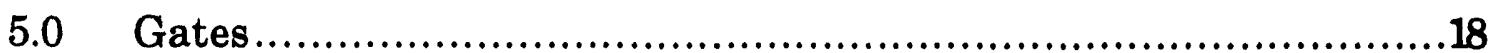

5.1 Design Criteria ..................................................... 18

5.2 Metallurgy ..........................................................21

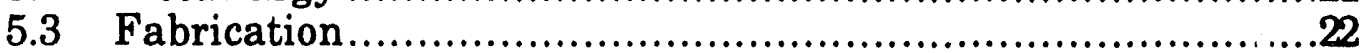

6.0 Sealing System Components..........................................22

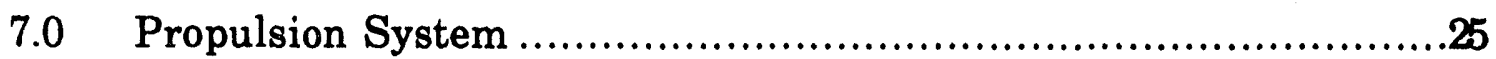

7.1 Reservoir Design and Fabrication ..................................25

7.2 Cradle Design......................................................26

7.3 Shaped-Charge Design and Selection............................26

7.4 Firing and Detonation System...................................27

7.5 Propulsion System................................................28

7.6 Pressures and Pumping System ...............................28

8.0 Arresting System ..................................................29

8.1 Honeycomb Deceleration Design and Fabrication..............29

8.2 Design of Mandrel and Latch Sleeve Rebound Attenuator .....30

9.0 Housing System (72-inch GSAC) ...................................

10.0 Diagnostic and Performance Instrumentation......................32 


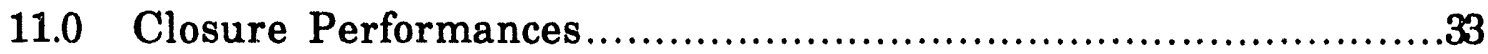

$12.0 \quad$ Future Design Considerations.............................................35

13.0 Procurement Philosophy and Cost ................................37

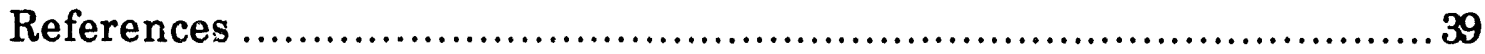

Appendix A: Early Closure Systems ......................................... 41

Appendix B: Characteristics of Large, Gas-Actuated Closures............51

\section{Figures}

1. Typical Testbed Configuration at the Nevada Test Site .................10

2. Thirty-inch Fast-Acting Closure .......................................11

3. Seventy-two-inch Gas Seal Auxiliary Closure .............................14

4. Gate Lightening Hole Patterns...........................................19

5. Strong Composite Gate for 62-inch Closure...............................20

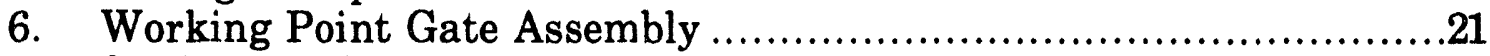

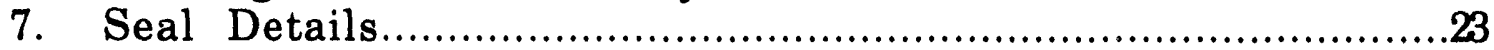

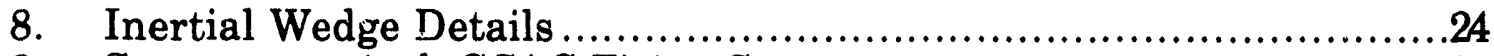

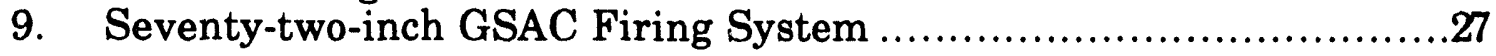

\section{Tables}

1. Chart Showing What Occurs Immediately After Detonation at a Station Located 300 Feet from the Working Point........................ 15

2. Chronology of Auxiliary Closures ...................................17

3. Summary of Gas-Actuated Pipe Closure Systems for Horizontal Line-of-Sight Tests at NTS .............................................34

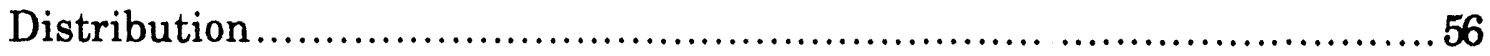




\section{History of Sandia National Laboratories' Auxiliary Closure Mechanisms}

\subsection{Introduction}

On December 18, 1950, President Harry S. Truman approved the recommendation that the Nevada Test Site (NTS) be established. An area was thus set aside to perform nuclear testing within the continental United States. Since then, the U.S. has conducted nuclear tests, both above and below the landscape, at NTS.

NTS is located 100 miles north of Las Vegas, Nevada and is a vast expanse of desert, mesas, and dry lakebeds covering 1350 square miles $\left(3500 \mathrm{~km}^{2}\right)$. It is operated by the Department of Energy (DOE) as a field laboratory for conducting nuclear tests sponsored by the Defense Nuclear Agency (DNA), Sandia National Laboratories (SNL), Los Alamos National Laboratory (LANL), and Lawrence Livermore National Laboratory (LLNL).

Since the beginning of nuclear testing, the testing community had to respond to national policy resulting from changing world conditions. The Limited Test Ban Treaty, which became law in 1963, forced all testing to be performed underground and mandated that radioactive gases be prevented from entering the atmosphere. Containing nuclear test debris became a primary concern. The phenomenology of containment is both a science and an art unto itself. Because the subject is vast and complicated, many volumes have been written on the science, the technology, the political significance, and the overall history of containment and its role in the test program.

Testing a nuclear device involves considerable expenditure of manpower, money, and materials; the major objective is to learn as much as possible from resulting data. Thus, understanding containment and protecting experiments and diagnostics from being destroyed by the detonation are paramount. This report documents one key element of the technology used in an underground test setup and records the history of SNL's participation in and contributions to the technology of auxiliary closure systems used in horizontal tunnel tests.

1.1 Underground Tests. Underground nuclear tests at NTS are conducted in either vertical shafts or horizontal tunnels. The principal purpose of the vertical shots is to research and prove warhead designs. Nuclear tests (performed in horizontal tunnels) assess the effects nuclear weapon radiation has on various materials, components, and products. The primary goal is to determine the survivability of military hardware and other nuclear weapons system components. 
Currently, these tests are the responsibility of the Department of Defense (DoD) through the DNA. Nuclear devices for the tests are provided by either LANL or LLNL. SNL and other contractors provide instrumentation and nonnuclear hardware.

Horizontal nuclear tests are conducted in tunnels dug a mile or more deep into a mesa at the NTS. A typical testbed configuration consists of a long, tapered, line-of-sight pipe. The large, welded-steel pipe is sealed at both ends; the air is evacuated from the pipe before the detonation. A nuclear device is placed at the small end of the pipe. Test chambers that contain experiments are positioned in and around the pipe at various distances from the nuclear device. Experiments are also placed on the massive steel dome at the large end of the pipe.

A diagnostic instrumentation package located near the nuclear device will measure the performance of the device; it will measure the emission rates, the spectra of neutrons, and gamma and $x$-rays. This information will provide an accurate assessment of the effects on the test objects.

Within tens of milliseconds after the device is detonated, massive gasdriven aluminum gates close. By closing, they protect the experiments positioned along the length of the pipe. These fast-acting closure mechanisms allow the prompt radiation to pass, but block debris and hot gases from continuing down the pipe. These mechanisms are essential components of the test setup. SNL is the major designer and developer of these closure systems.

1.2 Role of Closure Systems. A closure system is a mechanism designed to totally obstruct the line-of-sight, whether its purpose is to protect experiments from blast debris and radiation or to prevent the release of radioactive gases to the atmosphere before, during, or after the event. The major purpose of the closure systems designed and built by Sandia is to protect the experiments. This technology has evolved rapidly in the short history of underground nuclear testing.

The line-of-sight system allows recovery of experiments after they have been exposed to a nuclear detonation. This system uses a tapered horizontal line-of-sight (HLOS) steel pipe. The pipe is $\sim 6$ inches in diameter at the end where the nuclear device is placed; it can be more than 20 feet in diameter at the other end. The pipe is also $\sim 1000$ feet long. The experiments are situated at various distances from the nuclear device along the HLOS pipe and on and around the massive steel dome at the large end of the pipe. The HLOS system is sealed at both ends and air is pumped out of the system; this allows the unattenuated passage of nuclear radiation along the pipe. 
Stemming or filling the space between the HLOS and the surrounding tunnel with the proper material and the proper placement of the material is also an integral part of containing the radioactive debris and the gas that is generated by a nuclear blast.

The HLOS system is designed to allow the initial radiation from the nuclear explosion to impinge on the experiments and then to obstruct the pipe before debris and hot gases can affect or destroy the experiments. Ideally, the closure system would also seal off the gases associated with the nuclear detonation for an indefinite period of time. This is necessary not only to protect the experiments, but also to help prevent the expulsion of radioactive debris into the atmosphere.

The mechanical closures and the stemming seal off the HLOS pipe. The closure mechanisms prevent the flow of radioactive debris through the pipe. Of these mechanisms, some serve as a barrier to high-velocity debris and gas flow, and thereby protect a second group of slower-closing mechanisms that provide a gas-tight seal to ensure experiment protection and total containment.

Developing the closure systems has been an evolutionary process. The underground testing program has required a diversity of closure mechanisms. In response, Sandia has developed numerous fast-acting closure mechanisms since the mid-1960s. Generally, each closure has been custom designed to meet a specific requirement. Appendix A describes the function and performance of some of the more significant examples of early closures developed by SNL for use in tunnel shots.

\subsection{Closure Design Categories}

Figure 1 shows the current configuration for a typical testbed. The designs of the closure systems are based on experience and on concepts that have evolved since the mid-1960s. The three mechanical closure systems, i.e., the fast-acting closure (FAC), the gas-sealing auxiliary closure (GSAC), and the tunnel and pipe seal (TAPS) have been used in five tunnel tests:

- MIDDLE NOTE (3/87)

- MISSION CYBER (12/87)

- DISKO ELM (9/89)

- MINERAL QUARRY (7/90)

- DISTANT ZENITH (9/91). (DISTANT ZENITH also used the stemming anchor closure (STAC), that is discussed in Section 12.) 


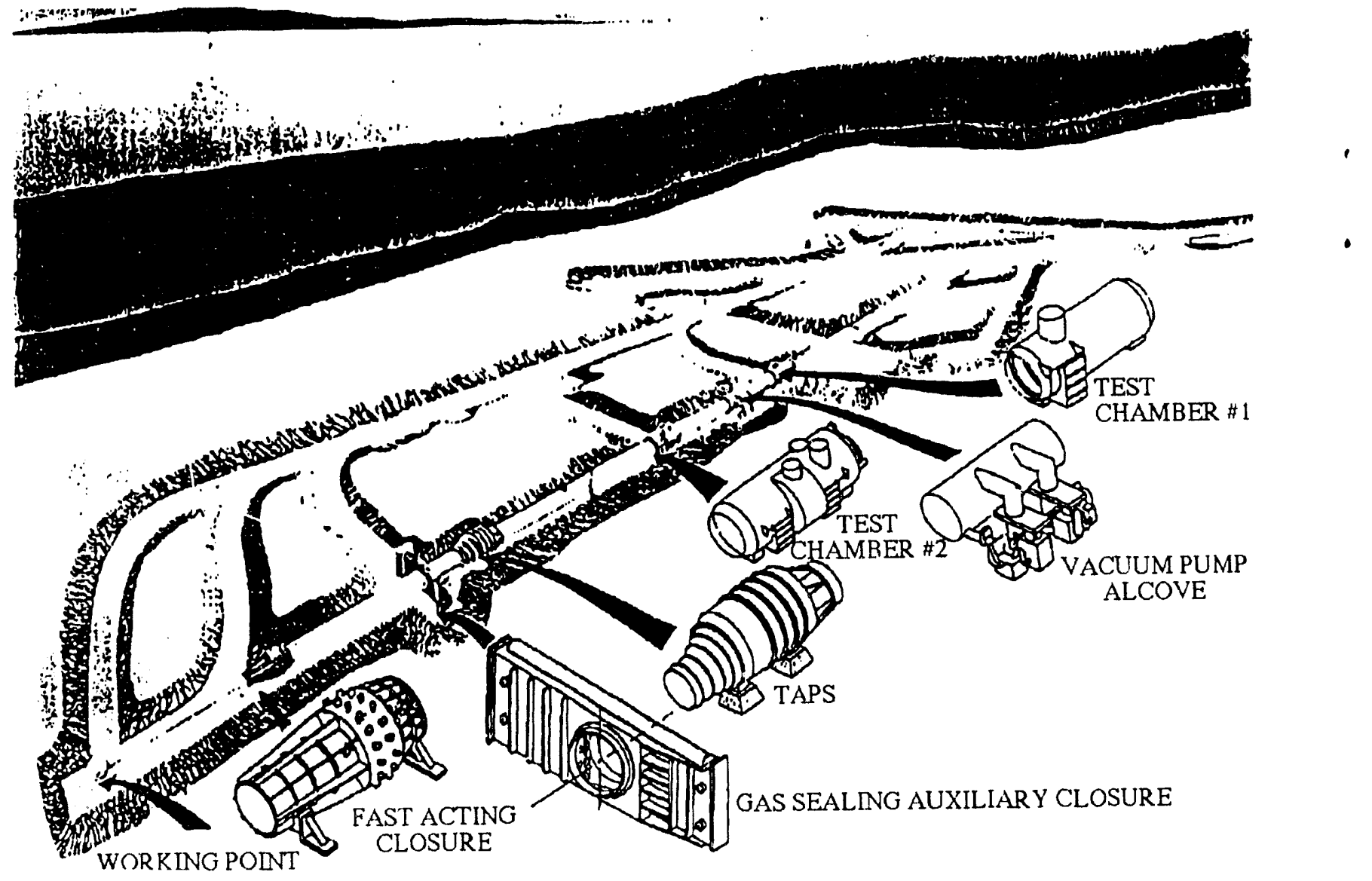

Figure 1. Typical Testbed Configuration at the Nevada Test Site

The FAC, STAC, and GSAC are Sandia designs; the TAPS was designed by Lockheed. A short description of the FAC and TAPS follows. The remainder of this report deals exclusively with the development and design of the GSAC.

2.1 FAC. The development of the currently used FAC (see Figure 2) has evolved since around 1980. The 30-inch FAC is an explosively driven containment device. It was designed and developed by Sandia for the DNA's low-yield underground nuclear tests. The FAC consists of three aluminum tubes assembled concentrically to form an aluminum plug/ closure spool that is bolted to a steel-transition flange and secured to the HLOS pipe. Approximately 450 pounds of high explosives are wrapped around the outside diameter of the aluminum tube assembly. The complete FAC assembly has a maximum diameter of 80.5 inches, is 136.5 inches long, and weighs $\sim 30$ tons. 


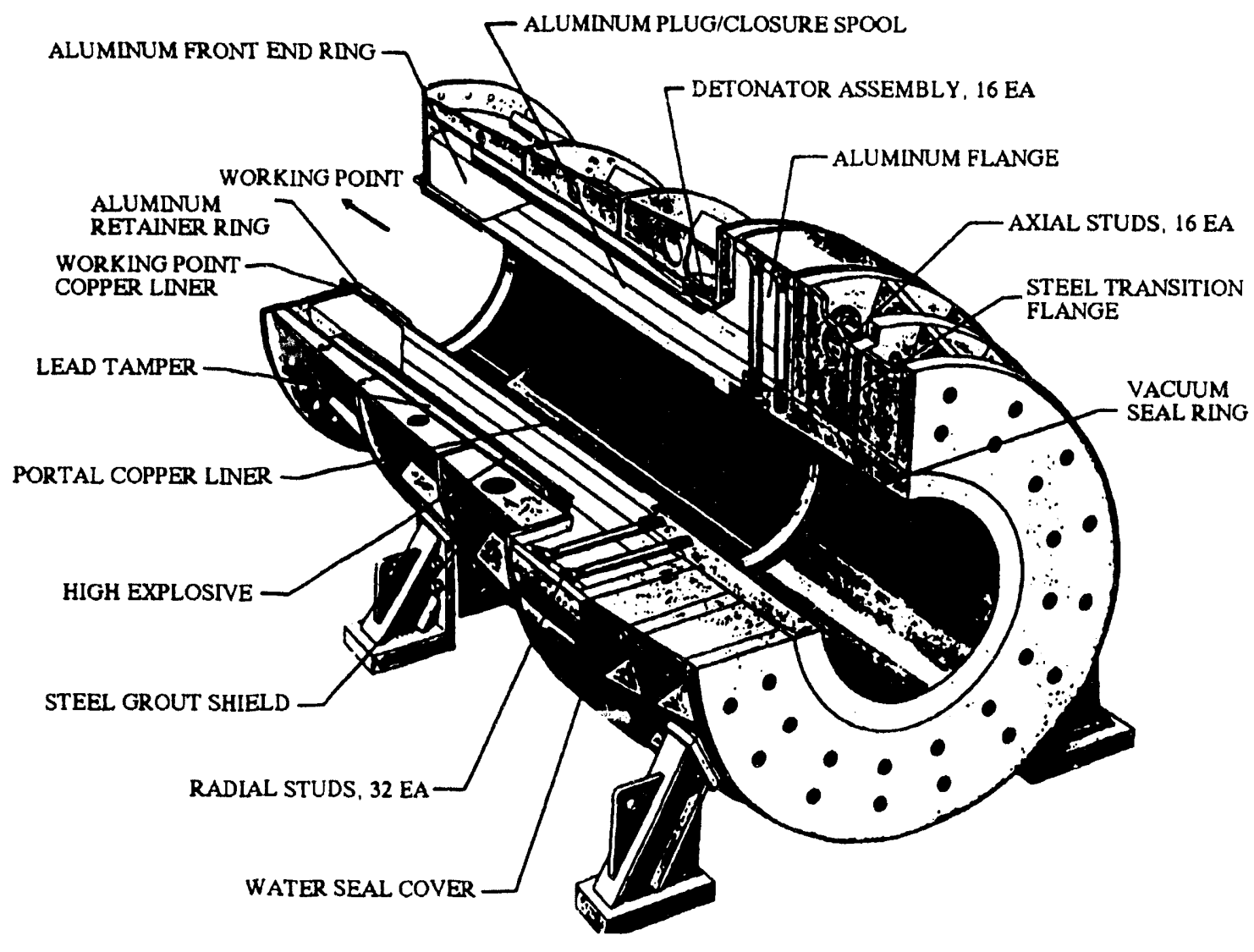

Figure 2. Thirty-inch Fast-Acting Closure

When the high explosives are detonated, the aluminum tubes are rapidly squeezed closed by detonation forces. The closed FAC prevents nuclear test debris from entering the HLOS pipe on the portal side of the FAC. The FAC is not gas tight, but can be partially sealed when the super-lean grout (that is placed around the FAC before the test) breaches and plugs small voids in the closed aluminum plug. The FAC is designed to close the 30 -inch inside diameter in $1 \mathrm{~ms}$ and to withstand ground shock loads of up to $3 \mathrm{kbar}$. A Sandia report, Development of a Fast-Acting Closure for Use in an Underground Nuclear Testbed, ${ }^{1}$ gives a complete history of this closure.

2.2 TAPS. The TAPS is a husky, simple-in-actuation unit. Basically, it is a very large swing-check valve that is held in the open (up) position by an explosively released latch system. At $100 \mathrm{~ms}$ after firing the nuclear device, the disk element is released and impacts the conical seat by gravity fall. Automatic sprags (latches) engage to hold the disk into the seat. Serrated concentric steel "teeth" impress into the soft aluminum seat. A secondary shock attenuation and low-temperature seal is provided by a large elastomer o-ring-type element. Time of actuation is $900 \mathrm{~ms}$. 
The principal TAPS shortcoming is the iong actuation time. Ground shock can distort the hinge mechanism and prevent the disk drop. Also, debris on the seat can preclude a good seal. If the seal could be accomplished in $40 \mathrm{~ms}$ with a GSAC design, the shortcomings could be eliminated. The fabrication cost would be $\sim 15 \%$ greater than a similar, modified auxiliary closure (MAC). If the TAPS could be eliminated in favor of the GSAC, $\sim \$ 500,000$ in fabrication and installation costs could be saved.

2.3 GSAC. The current GSAC (see Appendix A) had several precursors. The Fast Gates, used on the CYPRESS (2/69) and CAMPHOR (6/71) events in " $G$ " Tunnel, preceded the advent of the auxiliary closure. In the Fast Gate design, a number of cylinders charged with helium provided the propulsion and explosive bolts held the gate at rest. Fred Sweet ${ }^{2}$ and Clarence Myers were the principal developers of this design.

The auxiliary* closure concept began in 1968. The designers were R. E. Stinebaugh ${ }^{3}$ and T. O. Hunter. Area III gun tests verified the gas propulsion code. The first full-scale unit, called a Sandia auxiliary closure (SAC)** was fired near the Area III Thunderwell in November 1971. This unit was refurbished and used for the MISTY NORTH event in May 1972.

The first SAC used the primary design concepts of the current design listed below, with the exception of the gas-sealing capability.

- The high-pressure gas reservoir is instantly severed by a shaped charge.

- High-density aluminum honeycomb blocks absorb the gate kinetic energy.

- Tapered-steel mandrels, mounted in the gate forward end, engage and plastically deform tubular steel sleeves mounted to the body. These mandrels prevent the gate from rebounding.

- Forged 7075 aluminum gates (two per closure) have a multiplicity of bored holes. The holes lighten and permit proper heat treatment of the gates. The gates move in opposite directions and slide past one another; they cut obscuration time to $56 \%$ of the full closure time required for one gate.

\footnotetext{
*The name "auxiliary" was given because the normal upstream LOS pipe collapse has to be the primary impediment to stemming flow. Ingestion into the broken LOS pipe of stemming and other materials is literally squeezed down the pipe. Stopping this flow is the purpose of the auxiliary closure.

**DNA adopted the SAC design, renamed it a DAC (Defense [Nuclear Agency] auxiliary closure), and used it in numerous underground tunnel tests from 1972 until 1974. The SAC and DAC units were identical designs and served the same purpose.
} 
The 72-inch GSAC development began in 1977. The concept was that the standard auxiliary closure design could be modified to incorporate an effective gas seal, in addition to retaining its primary role as a relatively fast experiment protection device. The sealing requirement would be the same as it is for the TAPS specification: $0-1000$ psi gas at temperatures up to $1000^{\circ} \mathrm{F}$.

The accomplishment of a gas seal incorporated into a high-speed debris barrier design introduced some problems that had to be solved. The first 72-inch closure had 4500-pound gates that closed in about $30 \mathrm{~ms}$ with a terminal velocity of about $240 \mathrm{ft} / \mathrm{s}$. Deceleration occurred in $\sim 5 \mathrm{~ms}$ in a distance of 6 inches. Deceleration was at a rate of $1300 \mathrm{Gs}$.

Some original design concepts for the new system were:

- A metal-to-metal seal on the portal gate face

- A method to prevent seal surfaces from scrubbing during gate transit

- High gate-translation forces, applied uniformly at seal periphery, are to develop only after the portal gate becomes stationary (is brought to rest)

- Development of these forces to be provided by working point gate deceleration

- Magnitude of gate-spreading forces to be predictable in magnitude, and not to vary with final working point gate rest position

- Floating gate mandrels to allow for gate spreading.

Laboratory model testing of the wedge load system and the metal-to-metal seal configuration were finished prior to completion of the original design.

Two units were fabricated from October 1979 to April 1980 at the L\&F Machine Company in Huntington Park, California. These units incorporated all the features listed above. The preceding design, a 72-inch MAC, was not a gas-seal ring unit, but was the first event closure to have a lightweight, welded body. All earlier event SAC and DAC units had entirely different body constructions, although the internal operational parts were essentially the same as those we use today. The first unit was tested in a simulated event key plug encapsulation in Sandia's G-tunnel at NTS on October 2, 1980. On October 29, 1980, the MINERS IRON event occurred. This event used the first operational GSAC.

Although the theory of operation seems simple, there are critical parameter relationships for proper sealing. It has required the experience of eight event tests to produce the desired seal. Appendix B lists the operational characteristics of these units and the chronological design changes. The postmortem disassembly and visual analysis of the MISSION CYBER 
unit was invaluable to the successful completion of the goal of a gas-tight seal. The first such inspection of an event unit occurred in September 1989.

\subsection{The GSAC Mechanical Closure System}

3.1 Operational Theory. The GSAC unit is basically a large, rectangular steel box containing two massive sliding gates: the working point gate and the portal gate. Each gate is 12 inches thick. These gates are driven closed, into an overlapped position, by the instantaneous release of high-pressure gas from tubular steel reservoirs located at each end of the box. The gates slide adjacent to one another and in opposite directions. Figure 3 shows the configuration and basic features. These GSAC units, which are encapsulated by hundreds of tons of concrete, are considered to be one-shot devices. The closure is designed to:

- Obscure the HLOS in $17.5 \mathrm{~ms}$

- Place a massive barrier across the HLOS pipe as the gates close $\sim 33 \mathrm{~ms}$ after the device is detonated.

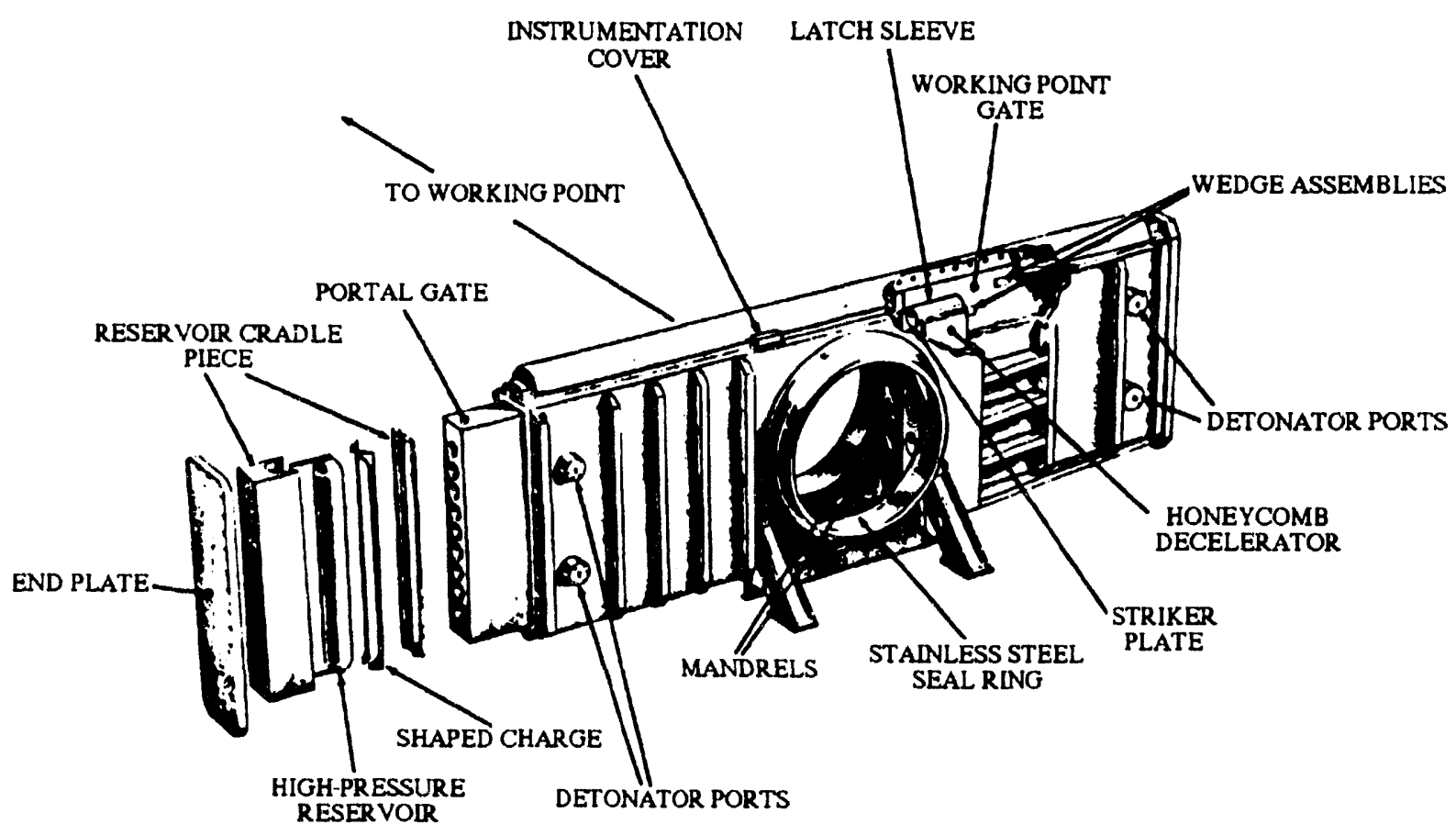

Figure 3. Seventy-two-inch Gas Seal Auxiliary Closure

This barrier is intended to intercept particulate debris based on the scenario given in Table 1. After closure, the barrier is intended to hold stemming materials from being forced toward the tunnel portal by the pressures and ground movements as a result of the nuclear explosion. Thus, the barrier aids containment and protects the experiments. 
Table 1. Chart Showing What Occurs Immediately After Detonation at a Station Located $\mathbf{3 0 0}$ feet from the Working Point

\begin{tabular}{|c|l|}
\hline Time & \multicolumn{1}{c|}{ Description } \\
\hline 9 to $12 \mathrm{~ms}$ & $\begin{array}{l}\text { iron gas }\left(10^{-2} \mathrm{~g} / \mathrm{cm}^{3}\right) \text { vapor, total mass } \sim 10 \mathrm{kgs}(22 \mathrm{lbs}) ; 1.5 \text { to } 2 \mathrm{~cm} / \mu \mathrm{s} \\
(49,000 \text { to } 66,000 \mathrm{ft} / \mathrm{s}) ; 1 \mathrm{~ms} \text { pulse }\end{array}$ \\
\hline 14 to $40 \mathrm{~ms}$ & $\begin{array}{l}\text { iron gas, water vapor, oxygen, then tuff and/or grout (small amount) } 0.5 \\
\text { cm/ } / \mu \mathrm{s}(16,400 \mathrm{ft} / \mathrm{s} ; \text { long duration, continuous push; } 500 \text { to } 1000 \mathrm{psi} \\
\text { stagnation pressure to ground shock }(40 \mathrm{~ms}) ; \text { density } \sim 1 \mathrm{gm} / \mathrm{cm}^{3} ; \\
\text { arrival just before ground shock }\end{array}$ \\
\hline $33 \mathrm{~ms}$ & $\begin{array}{l}\text { ground shock arrives; heavy grout and junk flow; pressure } \sim 4000 \text { to } 5000 \\
\text { psi stagnation pressure }(20 \mathrm{~ms}) 0.2 \mathrm{~cm} / \mu \mathrm{s}(6600 \mathrm{ft} / \mathrm{s})\end{array}$ \\
\hline 70 to $100 \mathrm{~ms}$ & $\begin{array}{l}\text { flow of general stemming material and junk arrives; this could cause } \\
\left.\left.\text { door failure; (up to } 10,000 \mathrm{psi} \text {; [density } 2 \mathrm{~g} / \mathrm{cm}^{3}\right]\right)\end{array}$ \\
\hline
\end{tabular}

The GSAC gates are essentially gas-driven pistons with rectangular dimensions of 81 inches high, 12 inches thick, and 85 and 94 inches long. Each gate weighs over 3 tons. A long, cylindrical gas reservoir that contains helium gas at 15,000 to 17,000 psi is located behind each gate at each end of the housing. At zero time, linear-shaped charges, oriented longitudinally on each reservoir, are initiated. The explosively formed jets sever the reservoir walls.

The sudden release of the compressed gas, augmented by the injected explosive energy, accelerates the gates. When each gate transits the LOS pipe, high-density aluminum honeycomb blocks are crushed and absorb the kinetic energy in 6 to 9 inches of travel. Rebound is limited by tapered steel mandrels, locked into the gates, which engage cylindrical tubes anchored to the body. The portal gate arrives and is stopped before the working point gate arrives.

The overlapped gates provide a barrier that resists penetration equivalent to that of 1-inch-diameter steel balls impacting at 15,000 ft/s. The GSAC overlapped gates also can withstand a static pressure load up to $22,000 \mathrm{psi}$.

Twelve wedge assemblies (see Section 4.0) are mounted on the inner face of the working point gate. When this gate impacts the honeycomb and decelerates, these assemblies activate to spread the gates apart and into tight contact with the body. A gas-tight seal is formed on the downstream face.

3.2 Function. The GSAC is designed to obscure the 72 -inch-diameter LOS pipe in $18 \mathrm{~ms}$ and to effect full closure with completely overlapped gates in $33 \mathrm{~ms}$. This barrier is intended to intercept particulate debris after obscuration and, after complete closure, to hold back stemming materials from 
being forced toward the portal by the pressures and ground movements resulting from the nuclear explosion. The gas-seal feature of the GSAC is intended to create a gas-tight, metal-to-metal seal after the sliding gates are at rest. These acts should aid successful containment, as well as protect the experiments.

3.3 Performance. The first SAC ( 60 inches in diameter) was designed to demonstrate a closure system that uses high pressure to close the gates in an unconfined, aboveground test. High pressures necessitated a massive housing. The aboveground test results were excellent, and this unit was adopted per se for tunnel use. Three years later, engineers had learned more about using stemming as a confining media, so a lighter, less costly housing was designed for underground installation.

On November 20,1974, the Sandia lightweight auxiliary closure (SLAC) was tested in an NTS simulated-tunnel installation. The test took place in the Area 12 " $G$ " tunnel facility. The new design had a 62-inch inside diameter. For this test, the reservoirs were pressured to 10,000 psi with nitrogen gas. The internal components and operating principles of the SLAC were essentially identical to the older SAC model. The major differences were that the SLAC used a completely redesigned, much lighter housing and larger-volume gas reservoirs. (See T. E. Stinebaugh's report: Sandia Lightweight Auxiliary Closure. ${ }^{4}$ ) Table 2 is a chronology of events, dates, and closures for all tunnel tests since 1971.

\subsection{GSAC Design Criteria}

4.1 Structural. The GSAC unit is placed downstream of either a MAC or a FAC, which are designed to take the brunt of the particulate and stemming flow. GSAC units are intended to offer secondary protection in the event of only partial containment by the primary closure and to provide a gas seal. With the use of helium instead of nitrogen, the GSAC gates have been redesigned. While they continue to maintain their speed, they are now substantially stronger.

With the gates in the final closed position, the wedges will have created a gap between the gates of $\sim 0.27$ inches. For stemming loads, this means that the working point gate is loaded first and transfers no load to the portal gate until substantial deflection brings the gates into contact. Only then is some of the load transferred to the portal gate. The MAC closures, designed for resistance to high stemming loads, have no gap between the gates. Both gates share the load equally which results in a higher failure load. Tests using a $1 / 23$ scale model indicate that failure of the overlapped GSAC gates is 11,000 to $22,000 \mathrm{psi}$, depending on the nature of the loading (i.e. depending on whether there is erosion, gas loading, or stemming loading). 
Table 2. Chronology of Auxiliary Closures

\begin{tabular}{|c|c|c|c|c|c|c|c|c|}
\hline Event & Date & Type & $\begin{array}{c}\text { Caes } \\
\text { (Ho or Ng) } \\
\text { (X-Exploedve) }\end{array}$ & $\begin{array}{r}\text { Brached } \\
(\mathbf{Y} \text { or N })\end{array}$ & $\begin{array}{l}\text { Dietance from } \\
\text { Working Point } \\
\text { (nt) }\end{array}$ & $\begin{array}{c}\text { Diameter } \\
\text { (in.) }\end{array}$ & $\begin{array}{c}\text { Obecure } \\
\text { LOS } \\
\text { (ms) }\end{array}$ & $\begin{array}{l}\text { Full } \\
\text { Closure } \\
\text { (ms) }\end{array}$ \\
\hline Develop. Model & $11 / 71$ & $\mathrm{SAC}$ & $\mathrm{N}_{2}$ & .- & - & 60 & Yes & Yes \\
\hline MISTY NORTH & $5 / 72$ & SAC & $\mathrm{N}_{2}$ & $\mathbf{Y}$ & 349 & 60 & Yes & Yes \\
\hline \multirow[t]{2}{*}{ DIAMOND SCULLS } & $8 / 72$ & SAC & $\mathrm{N}_{2}$ & $\mathbf{Y}$ & 358 & 60 & Yes & Yes \\
\hline & & SAC & $\mathrm{N}_{2}$ & $\mathbf{Y}$ & 348 & 60 & -- & .- \\
\hline \multirow[t]{2}{*}{ DIDO QUEEN } & $6 / 73$ & DAC & $\mathrm{N}_{2}$ & $\mathbf{N}$ & 372 & 62 & 02 & 32 \\
\hline & & DAC & $\mathrm{N}_{2}$ & $\mathrm{Y}$ & 322 & 55 & Yes & No \\
\hline \multirow[t]{2}{*}{ HUSKY ACE } & $10 / 73$ & DAC & $\mathrm{N}_{2}$ & $\mathrm{~N}$ & 372 & 62 & 17.5 & 32 \\
\hline & & DAC & - & -. & 322 & 55 & 16.0 & 31 \\
\hline \multirow[t]{2}{*}{ MING BLADE } & $6 / 74$ & SAC & $\mathrm{N}_{2}$ & $\mathrm{~N}$ & 450 & 60 & Yes & 40 \\
\hline & & DAC & - & -. & 380 & 52 & Yes & Unk* \\
\hline \multirow{3}{*}{$\begin{array}{l}\text { G-Tunnel Test } \\
\text { DINING CAR }\end{array}$} & $10 / 74$ & SLAC & $\mathrm{N}_{2}$ & -- & - & 62 & 16.5 & 29.5 \\
\hline & $4 / 75$ & DAC & $\mathrm{N}_{2}$ & $\mathbf{N}$ & 372 & 62 & Yes & 33 \\
\hline & & DAC & $\mathrm{N}_{2}$ & $\mathbf{Y}$ & 322 & 55 & 15.5 & 29 \\
\hline \multirow[t]{2}{*}{ HUSKY PUP } & $10 / 75$ & DAC & $\mathrm{N}_{2}$ & $\mathbf{N}$ & 372 & 62 & 19.6 & 32 \\
\hline & & DAC & - & - & 322 & 55 & -- & -- \\
\hline \multirow[t]{2}{*}{ MIGHTY EPIC } & $5 / 76$ & DAC & $\mathrm{N}_{2}$ & $\mathbf{N}$ & 372 & 62 & Unk & Unk \\
\hline & & DAC & $\mathrm{N}_{2}$ & $\mathrm{~N}$ & 322 & 55 & No & Yes \\
\hline \multirow[t]{2}{*}{ DIABLO HAWK } & $9 / 78$ & $\mathrm{MAC}^{\mathrm{a}}$ & $\mathrm{N}_{2}$ & $\mathbf{N}$ & 405 & 72 & 19.4 & 34.9 \\
\hline & & DAC & $\mathrm{N}_{2}$ & $\mathrm{Y}$ & 355 & 62 & 16.8 & 32.7 \\
\hline G-Tunnel Test & $10 / 80$ & GSAC & $\mathrm{N}_{2}$ & -- & - & 72 & 18.8 & 32.7 \\
\hline \multirow[t]{2}{*}{ MINERS IRON } & $10 / 80$ & GSAC & $\mathrm{N}_{2}$ & $\mathbf{N}$ & 375 & 72 & 18.5 & 32.7 \\
\hline & & MAC & $\mathrm{N}_{2}$ & $\mathbf{N}$ & 325 & 62 & 16.2 & 30.3 \\
\hline \multirow[t]{2}{*}{ HURON LANDING } & $9 / 82$ & GSAC & $\mathrm{N}_{2}$ & $\mathbf{N}$ & 370 & 72 & 18.7 & 32.9 \\
\hline & & MAC & $\mathrm{N}_{2}$ & $\mathrm{Y}$ & 320 & 62 & 15.0 & 30.5 \\
\hline \multirow[t]{2}{*}{ MIDAS MYTH } & $2 / 84$ & GSAC & $\mathrm{N}_{2}$ & $N$ & 360 & 72 & 18.4 & 33.7 \\
\hline & & $\mathrm{MAC}$ & $\mathrm{N}_{2}$ & $?$ & 310 & 62 & 14.9 & 26.8 \\
\hline \multirow[t]{2}{*}{ MISTY RAIN } & $4 / 85$ & GSAC & $\mathrm{N}_{2}$ & $\mathrm{Y}$ & 360 & 72 & 18.4 & 34.7 \\
\hline & & MAC & $\mathrm{N}_{2}$ & $\mathrm{Y}$ & 310 & 62 & 13.6 & No \\
\hline \multirow[t]{2}{*}{ MIGHTY OAK } & $4 / 86$ & GSAC & $\mathrm{N}_{2}$ & $\mathbf{Y}$ & 369 & 72 & 18.2 & 34.9 \\
\hline & & MAC & $\mathrm{N}_{2}$ & $\mathrm{Y}$ & 310 & 62 & 13.6 & No \\
\hline \multirow[t]{2}{*}{ MIDDLE NOTE } & $3 / 87$ & GSAC & $\mathrm{He}$ & $\mathrm{N}$ & 317 & 72 & 16.4 & 28.8 \\
\hline & & FAC & $\mathrm{X}$ & $\mathrm{N}$ & 136 & 30 & 1.00 & $1.5-2.0$ \\
\hline \multirow[t]{2}{*}{ MISSION CYBER } & $12 / 87$ & GSAC & $\mathrm{He}$ & $\mathrm{N}$ & 393 & 72 & 18.0 & 33.0 \\
\hline & & FAC & $\mathrm{X}$ & $\mathrm{N}$ & 144 & 30 & 1.00 & $1.5-2.0$ \\
\hline \multirow[t]{2}{*}{ DISKO ELM } & $9 / 89$ & GSAC & $\mathrm{He}$ & $\mathrm{N}$ & 393 & 72 & 17.4 & 32.8 \\
\hline & & FAC & $\mathrm{X}$ & $\mathrm{N}$ & 144 & 30 & 1.00 & $1.5-2.0$ \\
\hline \multirow[t]{2}{*}{ MINERAL QUARRY } & $7 / 90$ & GSAC & - & $\mathrm{He}$ & 515 & 72.0 & 18.4 & 34.30 \\
\hline & & FAC & $\mathrm{X}$ & -- & 199 & 30 & 1.00 & $1.5-2.0$ \\
\hline \multirow[t]{3}{*}{ DISTANT ZENITH } & $9 / 91$ & GSAC & $\mathrm{He}$ & $\mathbf{N}$ & 451 & 72.0 & 16.7 & 30.9 \\
\hline & & STAC & $\mathrm{He}$ & $\mathrm{N}$ & 298 & 50 & 12.0 & 20.7 \\
\hline & & FAC & $\mathbf{X}$ & $\mathrm{N}$ & 179 & 30 & 1.00 & $1.5-2.0$ \\
\hline \multirow[t]{2}{*}{ HUNTERS TROPHY } & $9 / 92$ & GSAC & $\mathrm{He}$ & $\mathrm{N}$ & 393 & 72.0 & 18.0 & 33.6 \\
\hline & & FAC & $\mathrm{X}$ & N & 151 & 30 & 1.00 & $1.5-20$ \\
\hline
\end{tabular}

aModified Auxiliary Closure, originally called "72-inch SLAC."

*Unknown 
4.2 Location. The gates must effect closure and seal prior to the arrival of ground shock, which will occur at $\sim 40 \mathrm{~ms}$ after detonation. GSAC units have been installed between 317 and 451 feet from ground zero. When installed beyond a FAC unit, the working point gate must also arrest copper liner ejecta from the collapsing tube.

4.3 Performance. All units have functioned within the design times. With the exception of DISKO ELM, the gas-sealing function has been completely successful to date, although every unit has demonstrated that the basic design theory is sound. As postmortem data are reviewed, slight changes are made in each successive design to promote more effective sealing. A postmortem examination of the MISSION CYBER unit yielded invaluable information as to the dynamics of the inertial wedge gate spreading system.

The GSAC unit has been used on the following events:

- MINERS IRON (10/80)

- HURON LANDING (9/82)

- MIDAS MYTH(2/84)

- MISTY RAIN (4/85)

- MIGHTY OAK (4/86)
- MIDDLE NOTE (3/87)

- MISSION CYBER (12/87)

- $\quad$ DISKO ELM (9/89)

- MINERAL QUARRY (7/90)

- DISTANT ZENITH (9/91)

\subsection{Gates}

5.1 Design Criteria. The gates are the most critical element of the closure. They must structurally resist the various regimes of extreme flow of early gas and plasma products and the slightly later arrival of high-velocity stemming materials. Also, GSAC placement downstream of a FAC unit requires capturing high-velocity copper ejecta from the liner.

An accurate knowledge of gate structural loadings during gate closing is unavailable, although some measurements have been made over the years. Additionally, a large number of overlapped gates have been breached. Thirty-three percent of all gates (two gates per closure) have been breached structurally (see Table 2). Nominal stress calculations have been performed to identify the associated failure criteria.

Although calculations for overlapped gate pressure at the threshold of yield stress may be reasonable, extending the prediction to actual failure is not possible without test data. A hydraulic loading device has been designed and is being used to conduct $1 / 20$ and $1 / 23$ scale model failure tests on current and experimental gate configurations. Failure modes, maximum static pressure, and absorbed energy were established.

Breaching the 62-inch MAC gates does not always cause failure of the LOS pipe containment system if the downstream closure (i.e., the 72-inch GSAC) remains structurally sound. The 62 -inch closure has generally 
been considered a sacrificial unit that may fail, but will slow the stemming flow to the point whereby the next closure will satisfactorily stop the flow.

The one-piece aluminum alloy gate designs have changed through the years. Some spatial hole patterns are shown in Figure 4. The holes reduce gate weight and carry quenchant flow so that the desired temper condition can be achieved.

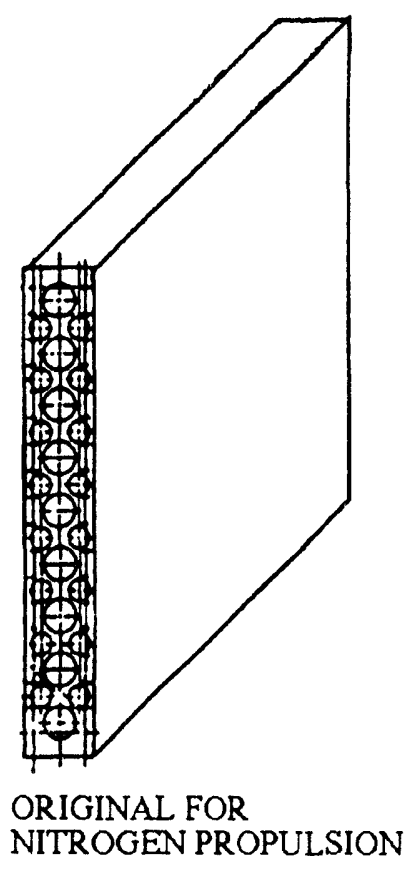

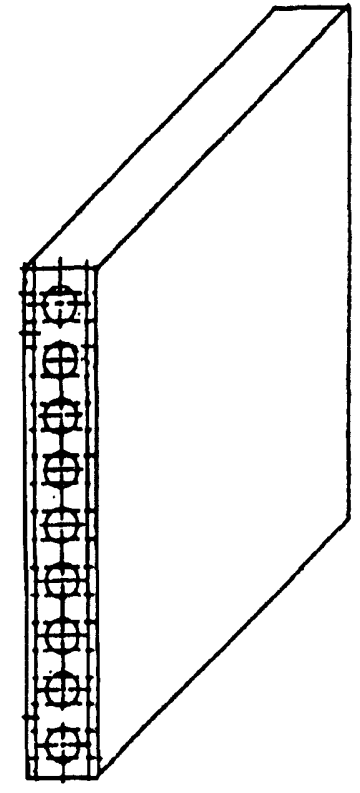

MODIFIED FOR HELIUM PROPULSION

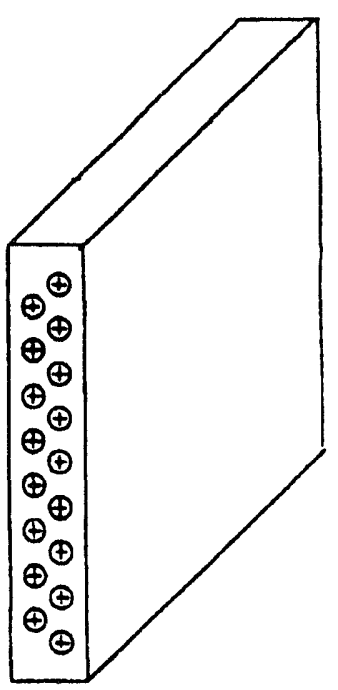

DESIGN FOR STAC CLOSURE

Figure 4. Gate Lightening Hole Patterns

Figure 5 shows a high-strength, composite gate design. The design uses an aluminum alloy core with $3 / 4$-inch-thick faceplates of alloy steel. This design will be used on 50 -inch through 62 -inch-diameter stemming closures (similar to a MAC unit). The design, however, is not appropriate for use on a GSAC.

When a closure functions, the gates are subjected to acceleration and deceleration forces. The 600 grains/foot flexible, linear-shaped-charges (FLSC) rupture the high-pressure gas reservoirs and drive a considerable elastic shockwave through the gate length. 


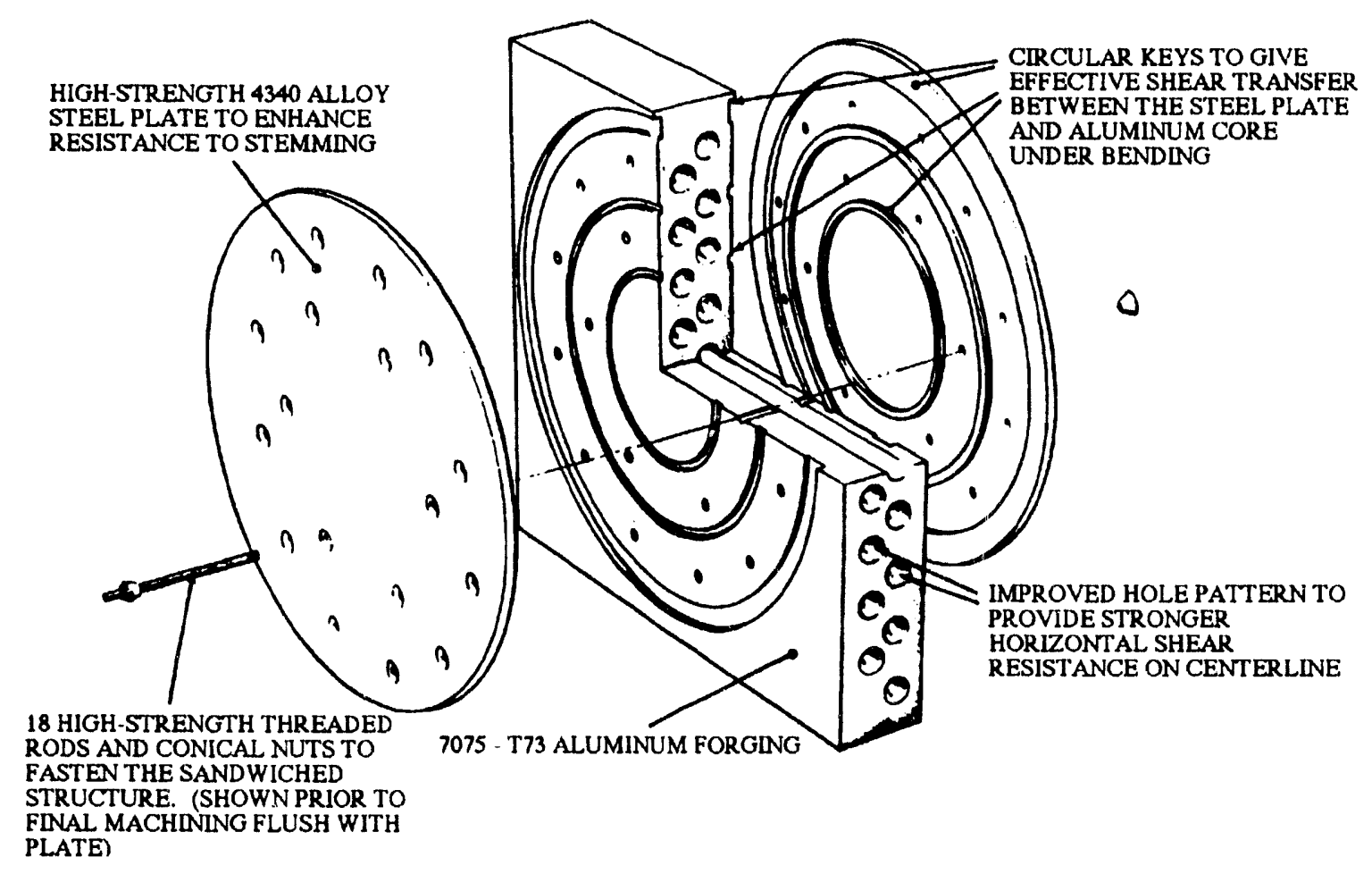

Figure 5. Strong Composite Gate for 62-inch Closure

A gate that has only the longitudinal lightening holes present should not suffer any structural consequences. However, cracks and damage have occasionally been noted during postmortem examination on gates that contained other features, such as the annular seal recesses on the 72-inch GSAC portal gate.

The working point gate (see Figure 6) has 12 milled cavities to accept the inertial wedge units. Shock problems could be reduced by using:

- A 400 grains/foot FLSC in place of a 600 grains/foot FLSC to rupture the reservoirs.

- A shock-mitigating cushion of material (i.e. honeycomb wafer) between the FLSC and the gate.

After MISSION CYBER, the small lightening holes were removed on both gates. The aluminum annular seal plate on the portal gate was also removed. The propensity for shock-induced gate cracking may have been eliminated. An additional gate shock occurs when the gate strikes the honeycomb decelerator at about $240 \mathrm{ft} / \mathrm{s}$. Deceleration is quite constant at $1200-1400 \mathrm{ft} / \mathrm{s}^{2}$. To date, this shock has caused no structural damage. 


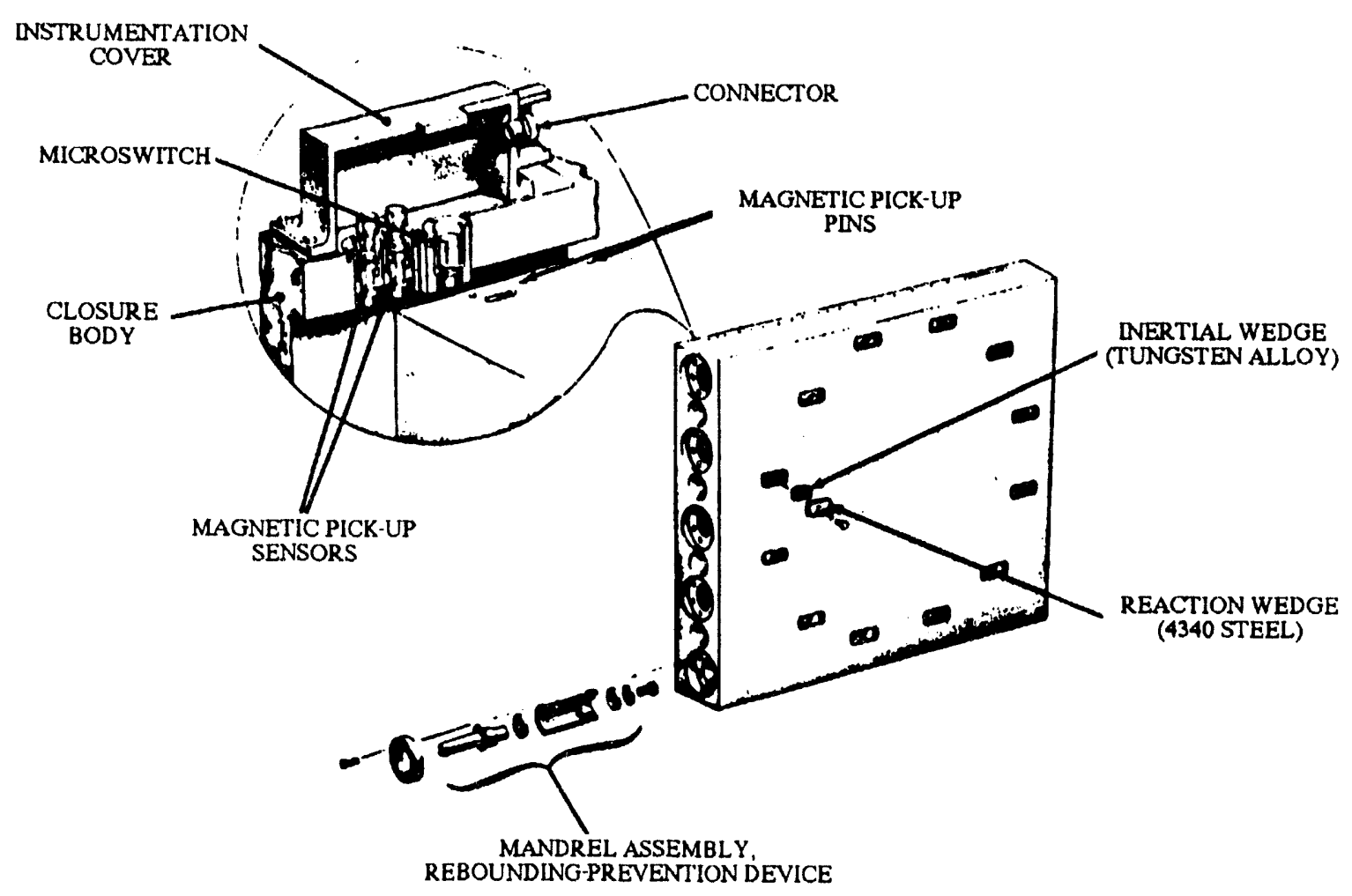

Figure 6. Working Point Gate Assembly.

5.2 Metallurgy. All gate closures in the MAC* and GSAC designs have been fabricated from 7075 aluminum alloy forgings. The forgings may represent the largest weight forgings produced in the U.S. The 7075 alloy is the strongest of all the aluminum alloys. Early closures used the T-6 temper, which provides the highest uniaxial strength properties.

A more recent temper used is the T-73; this tamper sacrifices a small amount of uniaxial strength for an increase in fracture toughness. This toughness is a very desirable property for closure gates. Recent $1 / 23$ scale model testing showed the T-73 temper to be superior to the T- 6 temper. This result was not expected. Typical tensile bar test properties (uniaxial stress) for the T-73 temper are:

*The components in the 62-inch MAC have basically the same design as the components in the 72-inch GSAC except it lacks those items associated with gas-sealing. The design has not been used since the introduction of the FAC in the MIDDLE NOTE event. However, all basic technological improvements incorporated in the GSAC and in the improved gate design from the scale model gate test program could be incorporated in the future. 
- 72KS1 ultimate

- $62 \mathrm{KS} 1$ yield

- $11 \%$ elongation.

5.3 Fabrication. All auxiliary closure gates have been 12 inches thick. For the 62-inch gate, a maximum width of 18 inches could be used. A thicker gate would be advantageous for higher velocity gates since it would reduce the deceleration problem by providing more honeycomb pressure area.

Current 62-inch MAC all-aluminum gate costs (as of 9/89) are \$31,000 for the aluminum alloy forging and $\sim 26,000$ for machining and heat-treating. Therefore, total cost per gate is $\sim \$ 57,000$. The total cost for the steel plate/ aluminum alloy gate design is $\sim \$ 69,000$.

\subsection{Sealing System Components}

The inertial wedge concept for creating the gate force required to form a metal-to-metal plastic seal has the following unique features:

- Automatic actuation at the required time (i.e., only after the portal gate is properly positioned at rest)

- Proper force placement around the port periphery

- Limited force magnitude irrespective of gate travel

- Repeatable force magnitude on each application.

A predicted and limited force magnitude irrespective of final gate position is essential. A calculated minimum force is required for full sealing of the portal gate surface onto the hardened stainless steel seal ring lips. However, too large a force could cause body weld fractures. Recent test data has indicated that 12 wedges create $6,000,000$ pounds of dynamic force to seat the double-seal lips $\sim 0.030$ inches into the hard aluminum face.

The intergate spreading forces are created by the 12 inertia wedges when the working point gate is decelerated. The portal gate arrives and stops in the proper position before deceleration of the working point gate starts.

Figure 7 shows the portal gate-body seal details. 


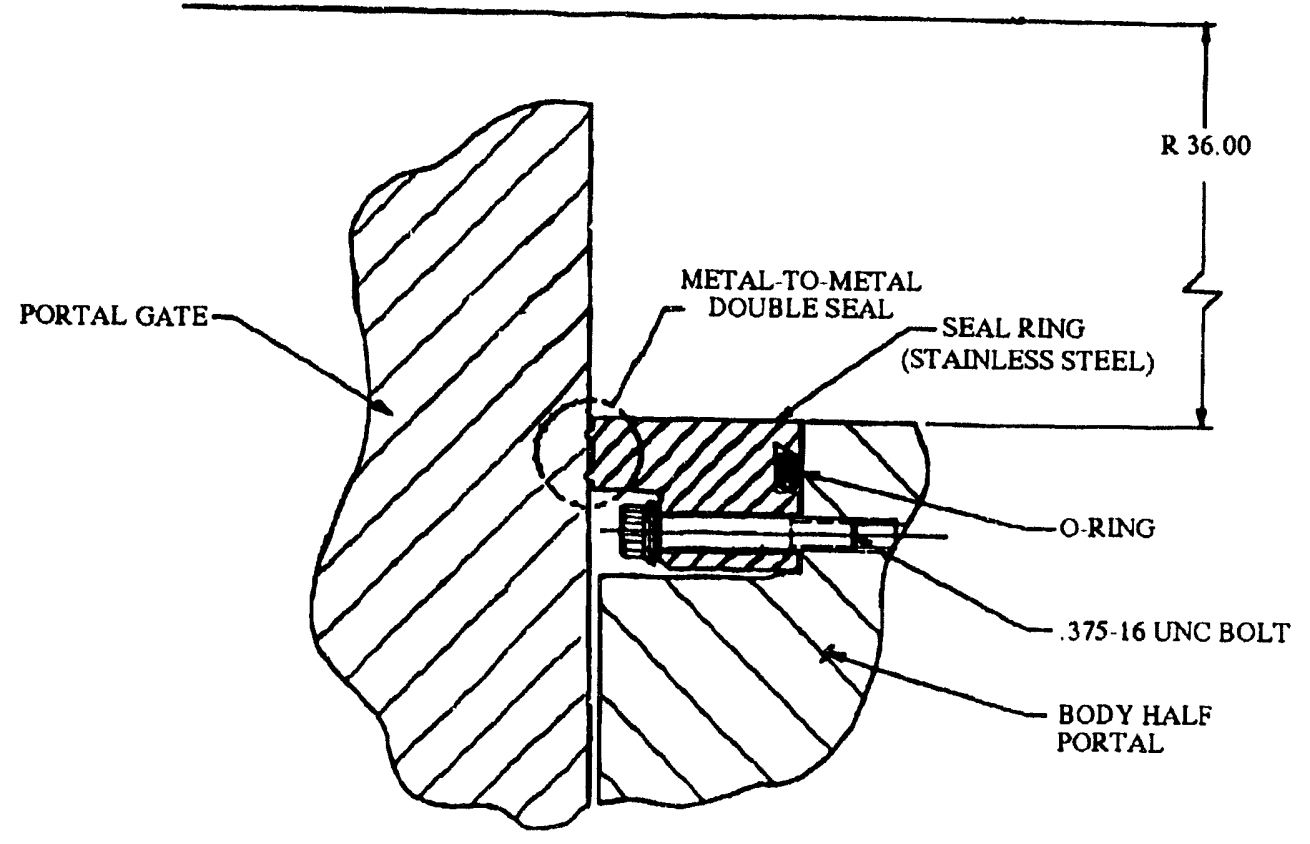

Figure 7. Seal Details

Figure 8 identifies the following:

- The inertial wedge that is fabricated from a tungsten alloy and weighs 11.68 pounds and the reaction wedge that is made from hardened steel. These parts are contained in milled cavities that are $7.87 \times 3.5 \times 2.0$ inches deep and are housed in the working point gate interface.

- The brass shear thimble and retention bolt that retain the wedges in the rest position during gate transit.

An isolation gap prevents the inertial wedge from being translated by the elastic shockwave created in the gate at the instant the shaped charges are initiated to sever the reservoirs. When the decelerator (honeycomb) is impacted by the working point gate, the forward relative motion of the inertial wedge causes the retaining lip shoulder of the shear thimble to shear off at a shear load just less than the failure strength of the cap screw and retaining threads in the gate material. The bolt stays intact during motion of the sheared thimble past the bolt head. A lengthwise slot in the inertial wedge allows relative motion between the wedge and the bolt. 


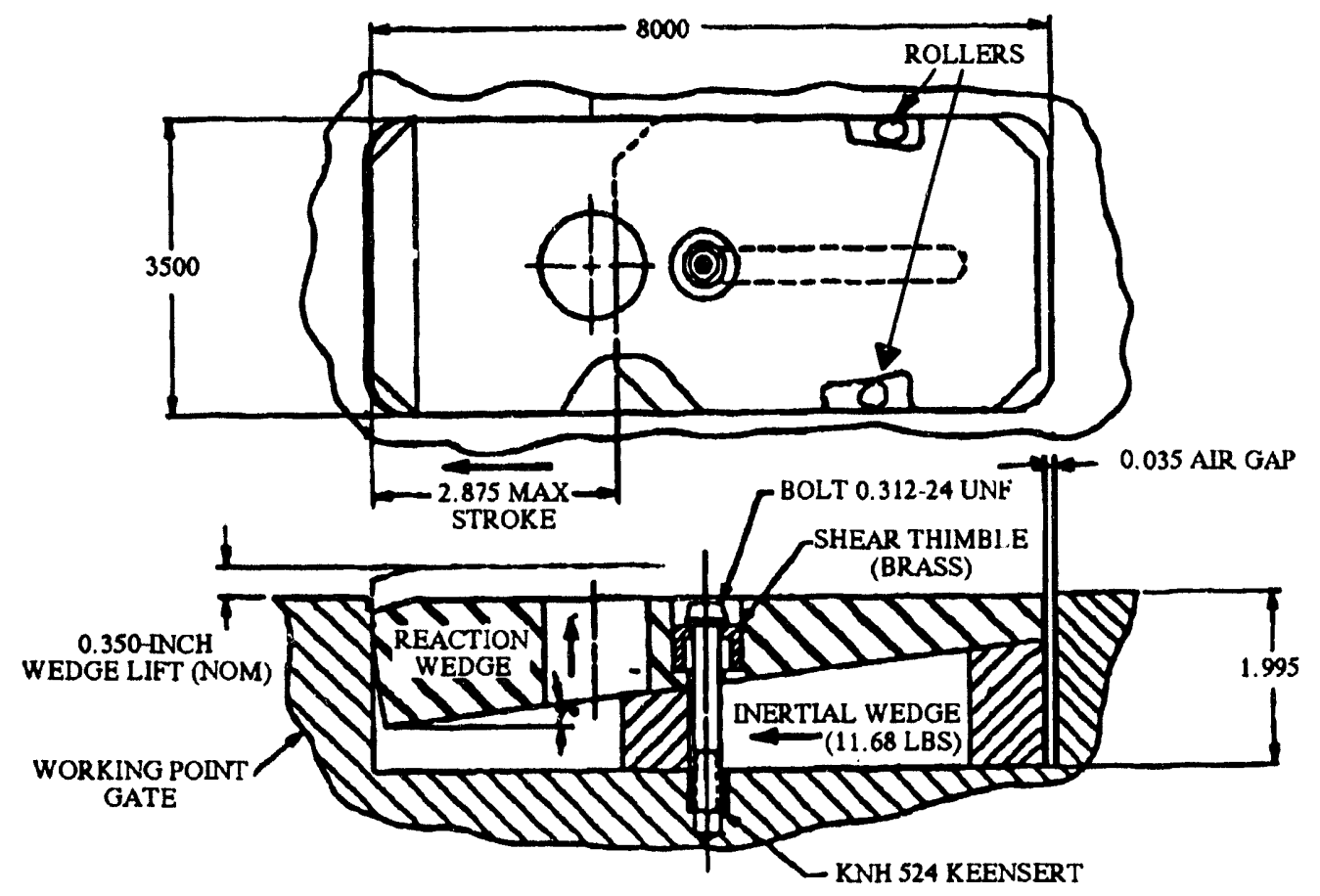

Figure 8. Inertial Wedge Details

The deceleration at $\sim 1800$ Gs causes the inertial wedges to be driven forward in the cavities. This then forces the reaction wedges out of the cavities. When the reaction wedges strike the inner face of the portal gates, the gates spread apart. All clearances are taken up and the portal gate surface is forced onto body seal ring projections. Both gates then conform to the adjacent body or seal plate surfaces, and a highly prestressed seal condition prevails (see Figure 8).

The seal force developed by the actuation of the twelve wedge assemblies is $\sim 2,000,000$ pounds $(8,750$ pounds per inch of seal periphery). The wedge force actuation lasts for $\sim 5$ to $6 \mathrm{~ms}$, which is the normal deceleration period. This time period is a function of honeycomb dynamic crush pressure (9700 psi to $11,800 \mathrm{psi})$ and gate impact velocity $(\sim 240 \mathrm{ft} / \mathrm{s})$.

Total wedge spread capability is 0.34 inches. Nominal requirement for a tight seal is about 0.24 inches. Wedge face angle is 7 degrees. Two 5/16inch-diameter $\times$ 5/8-inch-length rollers positioned in tapered recesses control wedge rebound. Total assembled weight is 18.77 pounds. See Figure 8 for details regarding the inertial wedge.

The 12 wedge assemblies are uniformly spaced on a 72-inch diameter. When the gates are in their closed position, the arrangement of the assemblies places the wedge forces along the metal-to-metal seal line. 
A computer code was developed to estimate wedge performance and to obtain an understanding of the effects of the following:

- wedge weight

- surface friction

- impact velocity

- deceleration field

- gate weights

- gate/body clearances

- body structural stiffness.

\subsection{Propulsion System}

7.1 Reservoir Design and Fabrication. There are two gas reservoir volume designs:

- 2.21 cubic feet for the 62-inch MAC and the 50-inch STAC closures

- 2.71 cubic feet for the 72-inch GSAC closure.

These reservoirs are seamless extruded tube and welded-on spherical head cap designs with a 10.50-inch outer diameter (o.d.) and a 9.05-inch inner diameter (i.d.). Material specification is $\mathbf{4 3 3 0}$ alloy steel vacuum arc remelt (VAR). The tubular portion is extruded with sufficient extra wall thickness to allow internal and external machining. External machining is required after heat treatment to the $180,000 \mathrm{psi}$ strength level to establish an accurate o.d. and cylinder straightness. This permits the cylinder to correctly fit into the cradle. The i.d. machining eliminates surface flaws that could lower burst integrity. There is a boss on each end of the cradle that is machined with a cone and threaded standard pressure tube fitting (autoclave 60,000 psi series). The following steps ensure that the reservoirs are reliable at over a 110,000 psi working stress:

- strict material control

- welding procedures

- heat treatment

- final inspection, weld $\mathbf{x}$-ray, and acoustic emission monitoring at proof pressure. 
Only two fabrication shops have built the reservoirs:

- D-Velco in Phoenix, AZ

- Sun Country Industries in Albuquerque, NM.

These sources were evaluated and qualified prior to using the reservoirs in a GSAC. A premature failure of a reservoir while holding high pressure, after closure installation at NTS, would require extremely costly and timeconsuming repairs.

7.2 Cradle Design. The purpose of the cradle is to position each reservoir and the two shaped charges accurately. The cradle also minimizes the void volume in the propulsion chamber and permits easy assembly of the reservoir into the closure. Two cradles are used per auxiliary closure. Each unit consists of two elements machined from 6061-T6 aluminum alloy forgings:

The 72-inch GSAC cradle dimensions are $12 \times 15 \times 81$ inches. The 62 -inch MAC and 50-inch STAC designs use an almost identical cradle as the GSAC except for height.

The longitudinally split cradle has segments of $260^{\circ}$ and $100^{\circ}$. The cradle positions the shaped charges to sever a $100^{\circ}$ segment of the reservoir, which permits the reservoir's expanding gas to accelerate the gates.

For prooftesting and long-term leak check of the high-pressure tube stubs to the reservoir bosses, the reservoir is lowered into position in the $260^{\circ}$ segment of the cradle prior to the makeup of the tubes. (This is the only way the makeup can be accomplished with the current design.) After leak qualification is completed, the reservoir cannot be removed from this portion of the cradle.

7.3 Shaped-Charge Design and Selection. Each reservoir's shaped-charge assembly conforms closely to the reservoir profile. Initiation of the shapedcharge assembly severs the 0.72-inch thickness of the cylindrical shell and the spherical end caps. The reservoir shell is cut into $260^{\circ}$ and $100^{\circ}$ segments. This angular arrangement, instead of the more usual $180^{\circ}$ split, was dictated by closure-body-width limitations and permits the maximum reservoir diameter for the available space.

A shaped-charge assembly, shown in Figure 9, consists of two actual charges in an aluminum holder. The holder orients and supports each shaped charge properly with respect to the reservoir. The only fabricator of these 600 grains/foot, copper-sheathed, chevron-shaped RDX-charges has been Jet-Research of Arlington, Texas. 
Optimum standoff for cutting (which is provided and maintained by the holder) is 0.60 inches. The holder has recessed areas that accommodate the positioning of two TC-217 EBW initiators per holder and four initiators per reservoir. \%

Tests have demonstrated that the 600 grains/foot charge will completely sever the reservoir wall thickness. A 0.375 -inch-thick layer of 45 pound/ cubic foot honeycomb material is placed between the shaped-charge holder and the gate to attenuate the structural shock effect on the gate.

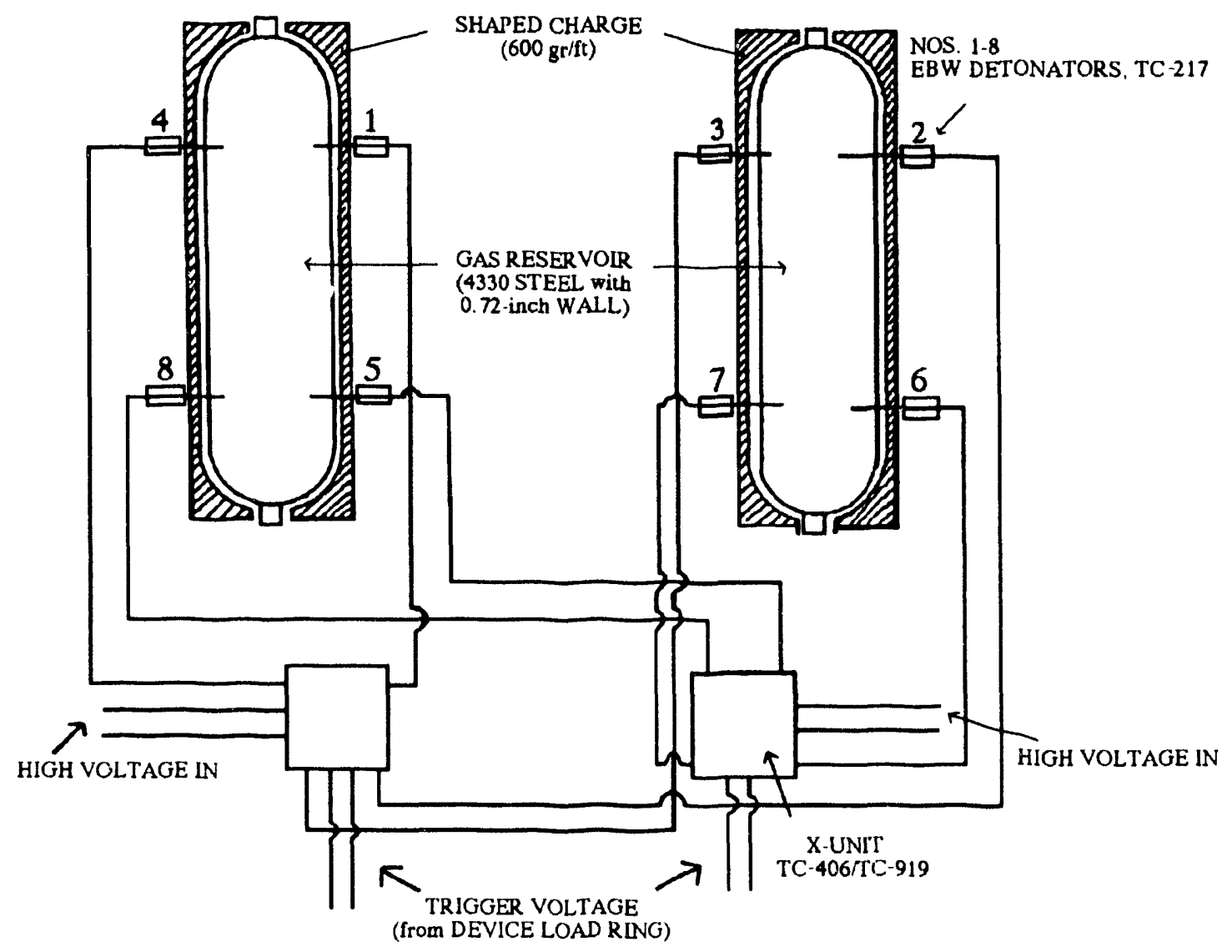

Figure 9. Seventy-two-inch GSAC Firing System

7.4 Firing and Detonation System. The firing system associated with the reservoir-shaped charges is shown in Figure 9. Each reservoir employs two shaped-charge assemblies, and each assembly has two exploding bridgewire (EBW) detonators. The TC-217 unit has 659 milligrams of PETN (Petaerythritoltetranitrate). Each of the four shaped charges for the 72inch GSAC contains 0.542 pounds of RDX explosive (cyclotrimethylenetrinitramine). 
The firing circuitry has double redundancy in that each of the four shaped charges has two detonators. The successful initiation of only one of these detonators will completely sever the reservoir on one side. The detonators for each shaped charge receive their firing signal from a separate fireset. Losing the function of one load ring would not impair closure operation. Additionally, each device fireset has two trigger circuits.

If detonation of only one of a reservoir's shaped-charges were to take place, the speed of gate closure would be drastically reduced due to gas throttling. Redundancy reduces the probability of this happening.

7.5 Propulsion System. The gate propulsion system has used compressed gas at pressures of 8,800 to 16,800 psi. Auxiliary closures from MISTY NORTH to and including MIGHTY OAK used nitrogen. If the gates were made stronger, i.e. heavier, this would slow down the closure times. Gasgun testing confirmed analytical predictions that for pressures above $\sim$ 4,000 psi, helium would provide greater propulsion than nitrogen. Helium was used on the last five events. For pressures of $16,000 \mathrm{psi}$, helium decreases the full-closure time of a GSAC by $20 \%$ with original weight gates, or helium can provide the original full-closure time for gates that are substantially heavier and stronger.

The shaped charge, which severs the gas storage reservoirs, introduces hot gases that boost the stored gas pressure and temperature. Sandia technical reports 5,6 give details on the propulsion system and provide performance tables for closure times.

Currently, much thought is being given to how propellants could provide faster gate operation. Possibly, gate-impact velocities could be increased from $240 \mathrm{ft} / \mathrm{s}$ to $320 \mathrm{ft} / \mathrm{s}$. Consideration would also have to be given to the accompanying increase in deceleration necessary to stop the gate.

7.6 Pressures and Pumping System. Gases that have been used for propulsion have been:

- Nitrogen for all SAC, DAC, MAC, and GSAC units from the MISTY NORTH event to and including the MIGHTY OAK event

- Helium for closures on 72-inch GSAC units employed from the MIDDLE NOTE event to and including the HUNTERS TROPHY event.

Early SAC and DAC units had reservoirs of 1.0 cubic feet volume and used pressures as high as $18,000 \mathrm{psi}$. Introduction of the MAC and GSAC designs increased reservoir volumes to 2.21 and 2.71 cubic feet, respectively. Pressures ranged from 14,000 to 16,800 psi. A percentage increase in reservoir volume is considerably more effective in providing greater gate propulsion than is a comparable percentage increase in gas pressure. At 16,000 psi, it would take a $36 \%$ reduction in gate weight to achieve a $20 \%$ 
faster closure time. The same effect is possible by changing from nitrogen to helium. Only GSAC units have used helium since no MAC units have been employed since MIGHTY OAK. Helium pressures used have been 8840 to $16,800 \mathrm{psi}$. At equal pressures and gate weights, helium provides about $20 \%$ faster operating times at 16,000 psi.

All high-pressure tubing is 60,000 psi-rated stainless steel with a $1 / 4$-inch o.d. and a 0.083 -inch i.d. The double soft-seated check valves on each of two delivery lines per closure are "in stemming" and are a precaution against post-shot gas leakage in the event of "out-of-stemming" line rupture due to ground motion.

Two types of reservoir tubing arrangements have been employed. All closures, until the introduction of the GSAC, have had individual and separate pumping. All MAC units also had this arrangement. GSAC units, except for one special case (DISKO ELM) have had reservoir pressure equalization. This is done to maintain the designed-in gate impact time differential $(7 \mathrm{~ms}$ ) required for proper wedge action and gas sealing. Pumping time for a GSAC with 16,000 psi helium is $\sim 6$ hours.

The Haskel pump is a three-stage, air-operated (80 to 90 psi) booster that takes the gas from standard cylinders at 2000 psi initial pressure and pumps the gas through a rather long tube system and into the reservoirs. The cylinders can be exhausted to about 300 psi. Approximately 27 helium bottles are required to boost the GSAC reservoirs to $16,000 \mathrm{psi}$. Gas is delivered to the lower fitting of a reservoir. The upper fitting tubing goes into a port on the HLOS pipe between the GSAC and TAPS unit. This port contains valving and pressure transducers. When required, the valves are used to exhaust the reservoirs. Transducers are used to monitor reservoir pressures during testing and the actual event.

Leak rates are monitored on the total pressure systems prior to and after stemming. Leak rates are also monitored between final pumping and the event. (One monitoring period was 5 weeks long.) Typical reservoir pressure loss rates are less than 12 psi per day.

\subsection{Arresting System}

8.1 Honeycomb Deceleration Design and Fabrication. The 72-inch GSAC gates, when propelled by 16,000 psi helium, impact the decelerator with 6.2 $x 10^{6}$ foot-pounds of energy. This is equivalent to the energy of a 3.3-ton truck traveling at $165 \mathrm{mph}$. The honeycomb used is either of $45 \mathrm{lb} / \mathrm{ft}^{3}$ or 55 $\mathrm{lb} / \mathrm{ft}^{3}$ aluminum honeycomb. Energy absorption capability is 560 footpounds per cubic inch and 660 foot-pounds per cubic inch, respectively.

The striking face net area for the 72 -inch GSAC is 846 square inches. The depths of honeycomb assemblies have been 14 and 16 inches, depending on energy requirements. The current use of 16,000 psi helium requires the 16 - 
inch depth of 45-pound honeycomb. Honeycomb crush is progressive and begins at the impact face. The deceleration value is appreciably constant over the total crush distance and is about 1050 to 1220 Gs for the current 72-inch GSAC gates. The dynamic crush strength of the $45 \mathrm{lb} / \mathrm{ft}^{3}$ honeycomb is $9680 \mathrm{psi}$, which is $20 \%$ higher than the static crush value. Current design crush distance is about 9 inches. Total available crush distance of the 16-inch deep block is 10.9 inches. Time of deceleration is about $6.7 \mathrm{~ms}$.

The honeycomb impact face dimensions are $11.50 \times 81$ inches with five each 4.50-inch-diameter holes bored through the 16-inch depth. These provide clearance for the latch sleeves. The gate impact face does not directly contact the aluminum honeycomb cell face. An aluminum plate is assembled against this face, and the gate strikes the plate.

The honeycomb material is an American Cyanamid product known as Hi-Grid. Cell size is 0.062-inch hex, and the aluminum alloy is 5052. A current R\&D effort is underway with Aztec/MCI Manufacturing, Inc. to develop a 304 alloy stainless steel honeycomb with an energy capability of at least 900 foot-pounds per cubic inch. With current weight gates, this would allow higher gate velocities.

8.2 Design of Mandrel and Latch Sleeve Rebound Attenuator. The mandrel and the latch sleeve devices are employed to resist gate rebound motion after the gate is brought to rest by the honeycomb. Current design has five mandrel assemblies attached into the impact face of each gate. There are correspondingly five tubular latch sleeves, coaxial with the mandrels, anchored to the housing decelerator support shelf. The latch sleeves are submerged in clearance holes through the honeycomb.

The mandrels are hardened alloy steel tapered rods. Each rod has a small end diameter of 2.440 inches. Taper ratio is 0.0356 inches per inch of diameter until a diameter of 2.707 inches is reached. The latch sleeves are 4340 VAR steel with 2.60 i.d. (straight hole, no taper) and 4.25 inches o.d. Maximum allowable latch sleeve hoop strain is about $4.3 \%$ to prevent cracking.

At approximately the same time the gate impacts the honeycomb decelerator striker plate, the tapered mandrel engages the open end of the latch sleeve. The male and female diameters match after 4.50 inches of engagement. As the gate decelerates, the mandrel engagement into the latch sleeve increases. The tubular latch sleeve is progressively expanded in i.d.

When the gate comes to rest, the mandrel has engaged the latch sleeve, 8.50 to 9.00 inches on the current design, and has stressed the latch sleeve wall into the plastic stress range (160,000 psi). This produces tremendous gripping forces that resist gate rebound. Any rebound is the result of elastic energy release and ground shock motions. 
The number of devices used per gate (four on MAC units and five on GSAC units) have performed extremely well. An on-going analysis and test program will continue to study the mechanics of operation. It may be possible to use fewer and lighter units. Although these units are installed for rebound control, they also reduce gate impact energy by $\sim 5 \%$, leaving the honeycomb $95 \%$ of the energy to absorb.

The mandrels are supported by flexible finger spring elements that make it possible to center on the latch sleeves during engagement. This allows the wedges to shift the gates apart as required for sealing to occur. For an analysis of operational characteristics, see Appendix B.

\subsection{Housing System (72-inch GSAC)}

The purpose of the housing (body) unit is to provide the following functions:

- Position and guide the gates through translation.

- Position the propulsion systems and provide a tight propulsion chamber.

- Position and support the honeycomb deceleration blocks and latch sleeves while they are slowing down and stopping the gates.

- Position and support the hardened steel seal ring.

- Position and support the eight shaped-charge detonators (TC-217) and gate-motion monitoring transducers.

- Provide structural resistance to deformation and failure due to propulsion chamber pressure, honeycomb decelerator crush loads, gate translation loads caused by inertial wedge action, and ground shock caused by the detonation of the device.

These functions cannot be accomplished by the current lightweight design without complete encapsulation in the high-strength concrete key plug. Standing alone, the 2.62-inch net thickness (after machining from the 3 -inch plate) is neither strong enough or stiff enough to sustain all the imposed loads.

This housing design uses welded and bolted construction. Each half is a stress-relieved and machined element that houses one each of the gate system, the propulsion system, and the decelerator and arrest system. When two halves are bolted together, a complete housing is formed. Except for the inlet and outlet stubs that are ASTM A-668 rolled ring forgings, material is either 3 -inch or 4-inch thick A-36 steel plate.

The mating flanges have no gasket seals. The large number of 1-3/4-inchdiameter alloy steel fully threaded rods (studs), washers, and nuts are installed with specially designed hydraulic tensioners. The end result is a 
load of $\sim 125,000 \mathrm{lbs}$ per threaded rod. Flange and stud sealing is accomplished by welding split pipe halves to the housing and by containing the flanges and studs within. Once the components are positioned within the housing, the endplates are attached with gask-o-seals and tensioned studs. This method of mechanically fastening together two machined weldments has eliminated earlier all-welded construction problems of warpage.

Since the housing really gets its stiffness and strength from the surrounding concrete, it is possible that plate thicknesses that are less than the current 3 inches could be used. This would reduce material and welding costs. The current material removal allotment for the weldment is 0.37 inches. From fabrication experience on 15 units of this construction to date, this amount seems about right. The resulting nominal wall thickness is 2.63 inches. Let us assume a reduction in plate thickness to 2.50 inches. After machining, the thickness would be 2.13 inches. With perhaps some increased depth of stiffeners, this would be an acceptable housing design for the future.

With the high-strength concrete encapsulation of the unit, the housing itself can be considered somewhat as a flexible bladder whose principal function is to provide sealing for the propulsion media. The compression strength of this concrete is 10,000 to $15,000 \mathrm{psi}$.

\subsection{Diagnostic Instrumentation and Performance}

It is of ultimate importance that accurate gate travel versus elapsed function time data is obtained for each gate. The reason is to check actual closing data with analytical predictions. A difference could indicate either a mechanical anomaly or an unsuspected early and/or stronger than expected flow of high-energy gases. vapors, plasmas, etc. The gates, under no-flow conditions, would show very close to calculated performance. Several G-tunnel tests, and other event tests with a FAC located toward the working point of the GSAC, have demonstrated this. Any substantial differences in the performance of the gates in actual events would probably relate to impinging flow.

The time-displacement data instrumentation consists of:

- Two magnetic sensors per gate located on the body and separated by a few inches

- Ferrous elements attached to the gates. Except for the last few closures, each ferrous element has been a six-pitch steel gear rack. Near the center of the rack, one tooth was removed to give a clear indication of approximate half-travel. Later closures substituted pressed-in steel dowels at selected and varying spacing.

Because there are fewer data points and less accelerated weight, the data is easier to reduce. The distance between the magnetic sensor pole pieces and 
the ferrous element (gear tooth or dowel) is 0.010 to 0.050 inches, depending on the gate's vertical motion. Redundancy is provided by using two sensors per gate.

By constructing continuous time/displacement curves for each gate, one with motion plotted to the right and one plotted to the left, the following can readily be determined:

- Obscuration time

- Gate full-closure time

- Decelerator impact time

- Gate velocity at impact

- Total deceleration time for each gate

- Accelerations and decelerations of each gate can be calculated.

Gate impact gauges (piezoelectric accelerometers) have been used on recent closures to indicate instantaneously each gate closure on the control point (CP) monitor screen. These transducers are mounted on the external surface of the housing and beneath the honeycomb. The shock transmitted through the honeycomb decelerator, at gate impact, generates a spike pulse from the transducer. A peak detector circuit uses this pulse to transmit a signal to the control point monitor.

Cavity pressure transducers look at the initial propulsion pressure at reservoir fracture and monitor the expansion pressure drop. The installation of these transducers should provide a way to study the dynamics of the gas propulsion and the boost in reservoir pressure contributed by the shaped charge. This monitoring attempt, however, has been unsuccessful. It appears that the pressure transducers required will have to be much more rugged. The standard fluid coupled plate (FCP) units may be more success-ful. These units incorporate a Kulite piezoelectric pressure transducer surrounded by a stiff metal bellows housing filled with silicone fluid.

\subsection{Closure Performances}

A chronological listing of auxiliary closures, including evaluation and event units, is shown in Table 3. All units are similar in basic design to the earlier design of the SAC and DAC units except for:

- The structurally enhanced gate capability

- The propulsion gas

- The increase in reservoir volume in the MAC and GSAC units. 
Table 3. Summary of Gas-Actuated Pipe Closure Systems for Horizontal Line-of-Sight Tests at NTS

\begin{tabular}{|c|c|c|c|c|c|c|c|c|c|c|}
\hline Event & Date & Gate & $\begin{array}{l}\text { Gate } \\
\text { Weight } \\
\text { (lb) }\end{array}$ & $\begin{array}{c}\text { Pressure } \\
\text { Area } \\
\text { (sp ft) } \\
\end{array}$ & $\begin{array}{c}\text { Reservoir } \\
\text { Primer Cord } \\
\text { (in) }\end{array}$ & $\begin{array}{l}\text { Reservoir } \\
\text { Sector Cut } \\
\text { (degrees) } \\
\end{array}$ & $\begin{array}{c}\text { Reservoir } \\
\text { Diameter } \\
\text { (in) }\end{array}$ & $\begin{array}{c}\text { Reservoir } \\
\text { Volume } \\
\text { (cu ft) }\end{array}$ & $\begin{array}{cc}\text { Reservoir } & \mathrm{T} \\
\text { Pressure } & \mathrm{X} \\
\text { (psi) } & ( \\
\end{array}$ & $\begin{array}{l}\text { Time } \\
X=3 \AA \\
(\mathrm{ms})\end{array}$ \\
\hline DIABLO HAWK & $9 / 78$ & 62-in DAC & 3820 & 5.65 & 143 & 180 & 7.0 & 1.00 & $18,000 \mathrm{~N}^{\mathrm{b}}$ & 19.2 \\
\hline MINERS IRON & $10 / 80$ & $\begin{array}{l}\text { 62-in MAC } \\
\text { (portal) }\end{array}$ & 4050 & 5.65 & 136 & 100 & 10.5 & 2.21 & $9,300 \mathrm{~N}$ & 19.5 \\
\hline MINERS IRON & $10 / 80$ & $\begin{array}{l}\text { 62-in MAC } \\
\text { (working point) }\end{array}$ & 4050 & 5.65 & 136 & 100 & 10.5 & 2.21 & $15,100 \mathrm{~N}$ & 17.2 \\
\hline HURON LANDING & $9 / 82$ & 62-in MAC & 4050 & 5.65 & 136 & 100 & 10.5 & 2.21 & $14,000 \mathrm{~N}$ & 17.0 \\
\hline MIDAS MYTH & $2 / 84$ & 62-in MAC & 4050 & 5.65 & 136 & 100 & 10.5 & 2.21 & $16,000 \mathrm{~N}$ & 17.0 \\
\hline MISTY RAIN & $4 / 85$ & 62-in MAC & 3650 & 5.65 & 136 & 100 & 10.5 & 2.21 & $16,000 \mathrm{~N}$ & 15.4 \\
\hline MIGHTY OAK & $4 / 86$ & $\begin{array}{l}\text { 62-in MAC } \\
\text { (both) }\end{array}$ & 3650 & 5.65 & 136 & 100 & 10.5 & 2.21 & $16,300 \mathrm{~N}$ & 15.4 \\
\hline DIABLO HAWK & $9 / 78$ & 72-in SLAC & 5200 & 6.48 & 161 & 180 & 8.0 & 1.56 & $14,900 \mathrm{~N}$ & 19.4 \\
\hline MINERS IRON & $10 / 80$ & 72-in GSAC & 5600 & 6.74 & 162 & 100 & 10.5 & 2.71 & $14,300 \mathrm{~N}$ & 18.5 \\
\hline HURON LANDING & $9 / 82$ & 72-in GSAC & 5600 & 6.74 & 162 & 100 & 10.5 & 2.71 & $14,300 \mathrm{~N}$ & 18.7 \\
\hline MIDAS MYTH & $2 / 84$ & 72-in GSAC & 5600 & 6.74 & 162 & 100 & 10.5 & 2.71 & $14,800 \mathrm{~N}$ & 18.0 \\
\hline MISTY RAIN & $4 / 85$ & $\begin{array}{l}\text { 72-in GSAC } \\
\text { (portal) }\end{array}$ & 5600 & 6.74 & 162 & 100 & 10.5 & 2.71 & $16,000 \mathrm{~N}$ & 18.3 \\
\hline MISTY RAIN & $4 / 85$ & $\begin{array}{l}\text { 72-in GSAC } \\
\text { (working point) }\end{array}$ & 6300 & 6.74 & 162 & 100 & 10.5 & 2.71 & $16,000 \mathrm{~N}$ & 18.4 \\
\hline MIGHTY OAK & $4 / 86$ & $\begin{array}{l}\text { 72-in GSAC } \\
\text { (portal) }\end{array}$ & 5600 & 6.74 & 162 & 100 & 10.5 & 2.71 & $16,300 \mathrm{~N}$ & 17.5 \\
\hline MIDDLE NOTE & $3 / 87$ & $\begin{array}{l}\text { 72-in GSAC } \\
\text { (portal) }\end{array}$ & 5600 & 6.74 & 162 & 100 & 10.5 & 2.71 & $12,840 \mathrm{He}^{\mathrm{c}}$ & 16.2 \\
\hline MISSION CYBER & $12 / 87$ & $\begin{array}{l}\text { 72-in GSAC } \\
\text { (portal) }\end{array}$ & 5600 & 6.74 & 162 & 100 & 10.5 & 2.71 & $8,840 \mathrm{He}$ & 17.4 \\
\hline DISKO ELM & $9 / 89$ & 72-in GSAC & 6600 & 6.74 & 162 & 100 & 10.5 & 2.71 & $15,300 \mathrm{He}$ & 16.3 \\
\hline MINERAI, QUARRY & $7 / 90$ & $\begin{array}{l}\text { 72-in GSAC } \\
\text { (portal) }\end{array}$ & 6600 & 6.74 & 162 & 100 & 10.5 & 2.71 & $15,300 \mathrm{He}$ & 16.5 \\
\hline \multirow[t]{2}{*}{ DISTANT ZENITH } & $9 / 91$ & $\begin{array}{l}\text { 72-in GSAC } \\
\text { (portal) }\end{array}$ & 6600 & 6.74 & 162 & 100 & 10.5 & 2.71 & $16,800 \mathrm{He}$ & 15.4 \\
\hline & & $\begin{array}{l}\text { 50-in STAC } \\
\text { (portal) }\end{array}$ & 6000 & 5.65 & 136 & 100 & 10.5 & 2.21 & $16,800 \mathrm{He}$ & 15.8 \\
\hline HUNTERS TROPHY & $9 / 92$ & $\begin{array}{l}\text { 72-in GSAC } \\
\text { (portal) }\end{array}$ & 6600 & 6.74 & 162 & 100 & 10.5 & 2.71 & $15,800 \mathrm{He}$ & 16.3 \\
\hline
\end{tabular}

Notes:

aAll gate times are in milliseconds

$b_{\mathrm{N}}=$ Nitrogen

${ }^{c} \mathrm{He}=$ Helium 
No closure has had a propulsion system failure or partial failure, other than on the working point gate of DAC 1 on MIGHTY EPIC. This was caused by a faulty high-pressure line fitting (blocked port) that precluded all gas from the reservoir. All other failures were partial or essentially total gate structural failures. There have been ten known closures with gate failures. A single gate failure does not necessarily mean a closure system failure and experiment damage.

Gate failures are caused by either early flows slowing the gates such that the arrival of stemming flows occurs before complete gate overlap, or overlap occurs before the arrival of stemming flow but the flow overloads the gates.

\subsection{Future Design Considerations}

There are three closure improvements that are desirable and probably achievable with an $R \& D$ program. These are: (1) propulsion, (2) arresting system, and (3) gate design.

- Propulsion. A propellant or explosive system could deliver considerably more energy to a gate. The current expansion characteristic of the reservoir gas has a drastic reduction of pressure after $20 \%$ of the total travel. The propellant system can maintain a more constant pressure for most of the stroke. This type of propulsion would eliminate the need for expensive reservoirs $(\$ 60 \mathrm{~K})$ and cradles $(\$ 60 \mathrm{~K})$.

- Arresting System. The current aluminum honeycomb system is extremely efficient as an energy absorber. However, considerably higher values of specific crush energy absorption $\left(\mathrm{ft}-\mathrm{lbs} / \mathrm{in}^{3}\right)$ should be developed to be compatible with higher gate velocities. A substitution of stainless steel for aluminum for the honeycomb could possibly double the current specific crush energy to about $1000 \mathrm{ft}-\mathrm{lbs} / \mathrm{in}^{3}$. However, this would mean higher shocks into the gate structure and could be a possible problem for future composite designs.

- Gate Design. The ultimate goals for gate structures are lighter weight and higher stemming resistance. Composite designs using metals and structural laminates (carbon-carbon, etc.) could be investigated. To design such a light, strong element that is static (already in place) is one thing, but to design a similar unit that must see high acceleration (i.e., $2000 \mathrm{Gs}$ ) and then undergo tremendous shock, deceleration, and temperature is much more difficult.

Another possible structural gate design candidate is one employing highstrength steel faceplates attached to a steel honeycomb core. The structural adhesive bonding between the honeycomb cell and the steel must meet the horizontal shear requirement and resist shock during gate transit and deceleration. 
Achieving the horizontal shear requirement at the center plane may be a problem, since it is at this point that the shears are the highest. Modification of the simplest three-element design (two faceplates and one honeycomb core) may be needed to meet all requirements.

A design currently in development testing is the 50-inch STAC. The STAC is designed to arrest stemming load induced by a nuclear explosion. It is very similar to a conventional 62-inch MAC, but has greater gate strength. The closure body, propulsion system, and the honeycomb deceleration system are similar in design to the 62 -inch MAC. The gates are the only major difference between the two systems. The 62-inch MAC used lighter, all aluminum gates in contrast to the steel/aluminum composite gates used by the 50 -inch STAC.

The steel/aluminum gates used in the 50-inch STAC basically consist of two 3/4-inch-thick, high-strength 4340 circular steel plates. The plates form a sandwiched structure when they are imbedded into the two sides of the 7075-T73 aluminum. (See Figure 5.) High-strength steel threaded rods and conical tapered nuts fasten the three pieces together. Mechanical circular keys and structural adhesive are used to ensure an effective transfer of the required horizontal shear stresses from the aluminum to the steel.

Preliminary studies have investigated the design of considerably larger gates than the $12 \times 81 \times 96.5$ inch gates currently used No larger aluminum forgings are currently available, even though aluminum plate designs have been explored for gates that would require a 110 -inch LOS pipe. These plates would be rolled to about 4.50 inches for a 7075 alloy design. The plates would be circularly keyed and fastened to form the structure. A 6061-T6 core, perhaps 6 inches in thickness, could be used with 7075 alloy faceplates 3 -inches thick.

One consideration would be to increase the gate width from 12 inches to 16 inches. This would achieve a much higher strength/weight ratio. In addition, it would lessen the deceleration problem by providing a greater honeycomb decelerator volume.

These three items - propulsion, arresting system, and gate design - are interrelated; no development of one of these can be performed without considering the other two. 


\subsection{Procurement Philosophy and Cost}

Because of the technical aspects of many of the closure components and because of the rigid specifications and inspection requirements (and in some cases the long lead times), several items are procured directly by SNL. These items for the 72-inch GSAC unit include:

- Gate forgings

- Cradle forgings

- Seal ring rolled-ring forgings

- Reservoir tube extrusions

- Reservoir end-cap forgings

- Reservoir fabrication

- Sole-sourced honeycomb decelerator blocks

- Sole-sourced, shaped-charge assemblies

- Detonator housing and sleeve components

- Wedge assemblies

- Gask-0-seals and sole-sourced o-ring seals

- Instrumentation

- High-pressure tubing and fittings.

Some of these items are sole-sourced because of the impracticality of developing additional sources for such low-volume procurement.

These items are generally on hand prior to placing the fabrication order for the balance of the required hardware and the final assembly. The three companies that have performed the heavy fabrication and assembly of these closures (MACs, DACs, and GSACs) are:

- L\&F Industries of Huntington Park, California

- Mountain States Steel of Provo, Utah.

- Allied Engineering and Production Company of Alameda, California. 
Other fabricators have submitted bids that were not competitive. The primary fabrication items for the mainframe are:

- Housing weldments, machining, and assembly

- Gate machining

- Cradle machining

- Striker plate machining

- Mandrel and latch sleeve machining.

Additionally, the fabricator assembles and vacuum tests the unit. These services are closely supervised by Sandia personnel who also perform or assist with some of the critical assembly operations.

It has become apparent that extremely close scrutiny by Sandia personnel of all procurement, fabrication, and assembly is essential to insure that the DNA receives a high-quality, dependable unit. Previous experience almost always reduces production problems. There is definitely a learning curve involver. Selecting a fabricator inexperienced in the building of these closures will most certainly cause problems.

The costs and time requirements are as follows:

- Cost. Supplying a 72-inch GSAC unit to DNA, within a 1992 timeframe, is $\$ 575,000$.

- Time. Total procurement time, after the mainframe order has been placed with a fabricator, is 9 months. This assumes that all the long lead-time forgings are available. Reservoir tube extrusions and end-cap forgings, honeycomb blocks, and shaped-charge assemblies have procurement times of 5 to 6 months. Gate forgings could possibly take as long as 8 to 10 months to procure. 


\section{References}

1. H. C. Walling and L. R. Hill, Development of a Fast-Acting Closure for Use in an Underground Nuclear Testbed, Sandia National Laboratories, SAND86-2907, September 1987.

2. F. R. Sweet, Post-Event Evaluation of the 60-Inch Fast Gates for Cypress, (OUO), Sandia Laboratories, SC-DR-70-121, July 1970.

3. R. E. Stinebaugh, 28.5-Inch Auxiliary Closure for Project Dido Queen HFR Experiment Canister, Sandia Laboratories, SLA-73-0590, August 1973.

4. R. E. Stinebaugh, Sandia Lightweight Auxiliary Closure (SLAC), Sandia Laboratories, SAND75-0082, February 1975.

5. M. D. Bennett and J. C. Weydert, Dynamics of Gas-Actuated Pipe Closures, Sandia National Laboratories, SAND86-1820, November 1986.

6. M. D. Bennett, Performance Tables for Helium-Actuated Pipe Closures, Sandia National Laboratories, SAND88-1079, October 1988. 


\section{Appendix A: Early Closure Systems}

The ciosure mechanisms discussed in this appendix were commonly used in tunnel shots from 1964 to 1972 . The data are presented as history; no bias is intended toward any specific system. In addition, we have chosen to mention only selected events that are representative of the evolutionary development of the HLOS systems:

- Gas Seal Valve

- Fast Gate

- High Explosive Vertical Door

- Debris Barrier System

- HE Dimple Closure

- Sample Recovery Canister

Gas Seal Valve. The gas seal valve was gravity-operated and designed to function as an HLOS gas seal. Installed in the middle of a tunnel plug through which the HLOS pipe passed, it was comprised of a large wedge/ seal plate and a housing assembly (see Figure A1).

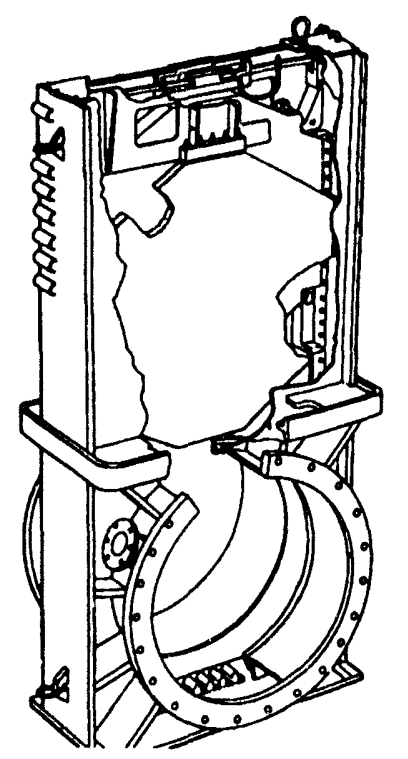

Figure A1. Gas Seal Valve

The wedge/seal plate was released by explosive bolts at detonation time. When released, the wedge/seal assembly was allowed to freefall, guided by the housing. A clearance of $3 / 16$ inch was maintained between the seal plate and the seals. 
After the wedge/seal plate assembly had dropped far enough to obscure the HLOS opening, the seal plate was stopped by a lead energy-absorbing system. The wedge plate continued to fall, and thereby caused the assembly to expand and the seal plate to be wedged against a metallic seal located in the seal ring. (See Figure A2.) (Note: This Sandia-designed closure mechanism served the same purpose as the TAPS* systems which were used by Test Command for the Defense Atomic Support Agency.) The gas seal valve was designed to withstand $1000 \mathrm{psi}$ burst pressure, $700^{\circ} \mathrm{F}$ (for an indefinite time), and a shock of $400 \mathrm{Gs}$. The overall height was 16 feet, and it weighed $\sim 52,000$ lbs. It was used in the CYPRESS event $(2 / 12 / 69)$.
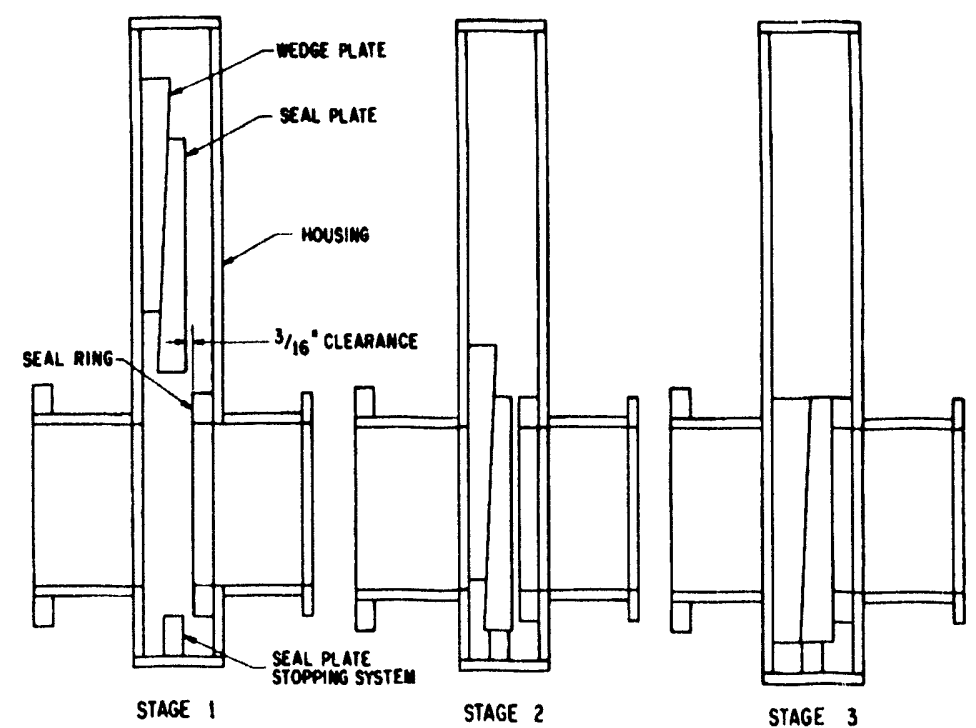

Figure A2. Operational Design of a Gas Seal Valve

Fast Gate. The 60-inch fast gate was a high-pressure gas-driven valve designed to act as a barrier to high-velocity debris traveling up the HLOS pipe. This mechanism used two opposing gates, each consisting of two 1-inch-thick annealed titanium plates driven together by 7000 psi helium gas pressure in $\sim 40 \mathrm{~ms}$. Deceleration of the gate assembly was done

\footnotetext{
*The DASA TAPS unit was designed against $1000 \mathrm{psi}$ and $1000^{\circ} \mathrm{F}$ for 20 minutes. The system consisted of a large hemispherical, gravity-operated door. The entire unit was encased in a massive, reinforced concrete plug poured into an enlarged keyway in the tunnel. Three sizes were built: (1) $51 / 4 \mathrm{ft}$ weighing $22,000 \mathrm{lbs}$; (2) $7 \mathrm{ft}$, weighing $34,000 \mathrm{lbs}$; and $81 / 2 \mathrm{ft}$. weighing $124,000 \mathrm{lbs}$. DASA used TAPS in the following events:
}

DOOR MIST (08/31/67)

DORSAL FIN $(02 / 29 / 68)$

HUDSON SEAL (09/24/68)
MING VASE (11/20/68)

DIESEL TRAIN (12/05/69)

DIANA MIST $(02 / 11 / 70)$
MINT LEAF (05/05/70)

HUDSON MOON (05/26/70) 
through a cylindrical grease pack, extruded lead bumpers, and springloaded stop pins that limited gate rebound. This Sandia-designed closure mechanism served the same purpose as the sample protection system* used by DASA's Test Command, but had the advantage of allowing the HLOS pipe to remain intact. The Sandia fast gate was designed to survive a $450-\mathrm{G}$ ground shock and weighed $\sim 28,000$ pounds. Two fast gates were used in the CYPRESS event $(2 / 12 / 69)$.

High-Explosive Vertical Door. This door was an explosively driven steel wedge that provided the primary gas seal to prevent the flow of hot gases through an LOS pipe. The 4870-lb. steel door was driven across a 65 -inchdiameter opening with 3800 grams (8-1/2 lbs) of nitroguanidine explosives within $38 \mathrm{~ms}$. The assembled door measured $\sim 196 \mathrm{in}$. high by $54 \mathrm{in}$. wide and weighed $79,000 \mathrm{lbs}$. It was designed to withstand $1000^{\circ} \mathrm{F}$ and $1000 \mathrm{psi}$. After its peak velocity of $2400 \mathrm{in}$./sec., the massive door was stopped by lead blocks and by locking fingers. The fingers at the top of the door engaged aluminum lock plates. The material flowing between the fingers locked the door at maximum downward travel.

The wedge-shaped steel door was seated against three copper seal rings on each side, which achieved the seal. The assembly was designed and fabricated for installation in the LOS pipe in two parts: (1) the HE chamber/ door was moved into the tunnel on a special dolly and suspended above the LOS by a rigid hoisting frame, and (2) the housing was moved into position and joined to the LOS pipe. The HE chamber was then lowered onto the housing and bolted in place.

The gas seal was obtained by three copper rings. The inside ring was designed so the pressure in the LOS would force the seal lip against the door surface and maintain the seal during expansion and contraction as the tunnel heated, then cooled. The door was stopped and locked in its sealing position in $44 \mathrm{~ms}$, or just before ground shock arrival, by impacting lead blocks in the bottom of the housing and by fingers machined on the lock plates.

\footnotetext{
* The SPS was a rectangular box placed in the LOS system between the working point and those items it was intended to protect. The vertical sides of the box formed doors comprised of two separate layers, an outer and inner 3/4-inch steel plate. These doors were driven into the LOS pipe by sheet high explosives. Each door placed a minimum of 1.5 inches of steel into the LOS. SPSs were used in pairs. Closure time was -20 ms. DASA used SPSs in the following events:
}

MIDI MIST $(06 / 26 / 67)$

DOOR MIST (08/31/68)

DORSAL FIN (02/29/68)

HUDSON SEAL $(09 / 24 / 68)$

MING VASE (11/20/68)
DIESEL TRAIN (12/05/69)

DIANA MIST $(02 / 11 / 70)$

MINT LEAF (05/05/70)

HUDSON MOON $(05 / 26 / 70)$ 
Debris Barrier System. Designed to protect the scientific experiments along the HLOS from airborne debris following detonation of the nuclear device, the DBS units (Figure A3) were encased in a vacuum shroud with a maximum diameter of $15 \mathrm{ft}$. by $3 \mathrm{in}$. and were either freefalling or were pneumatically driven closed at detonation time. The door of the first DBS unit used in an event was constructed of bungee cord and fiberglass on an aluminum frame. Successive DBS units were all metal. The DBS units were placed in the HLOS pipe on the working point side of each scientific station. Figure A4 is a side view showing the DBS operation. DBS units were used in pairs on the following events:

DIESEL TRANN

DIANA MIST
$12 / 05 / 69$

$02 / 11 / 70$ $\begin{array}{ll}\text { MINT LEAF } & 05 / 05 / 70 \\ \text { HUDSON MOON } & 05 / 26 / 70\end{array}$

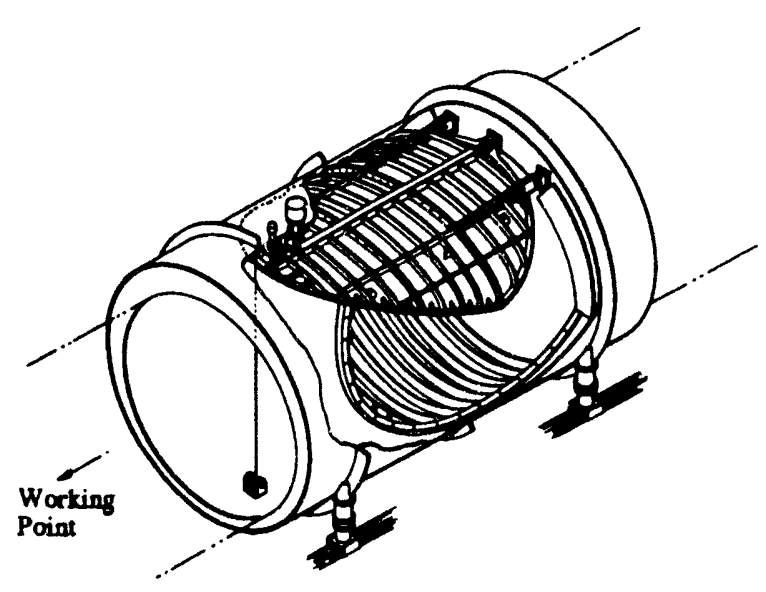

Figure A3. Debris Barrier System 


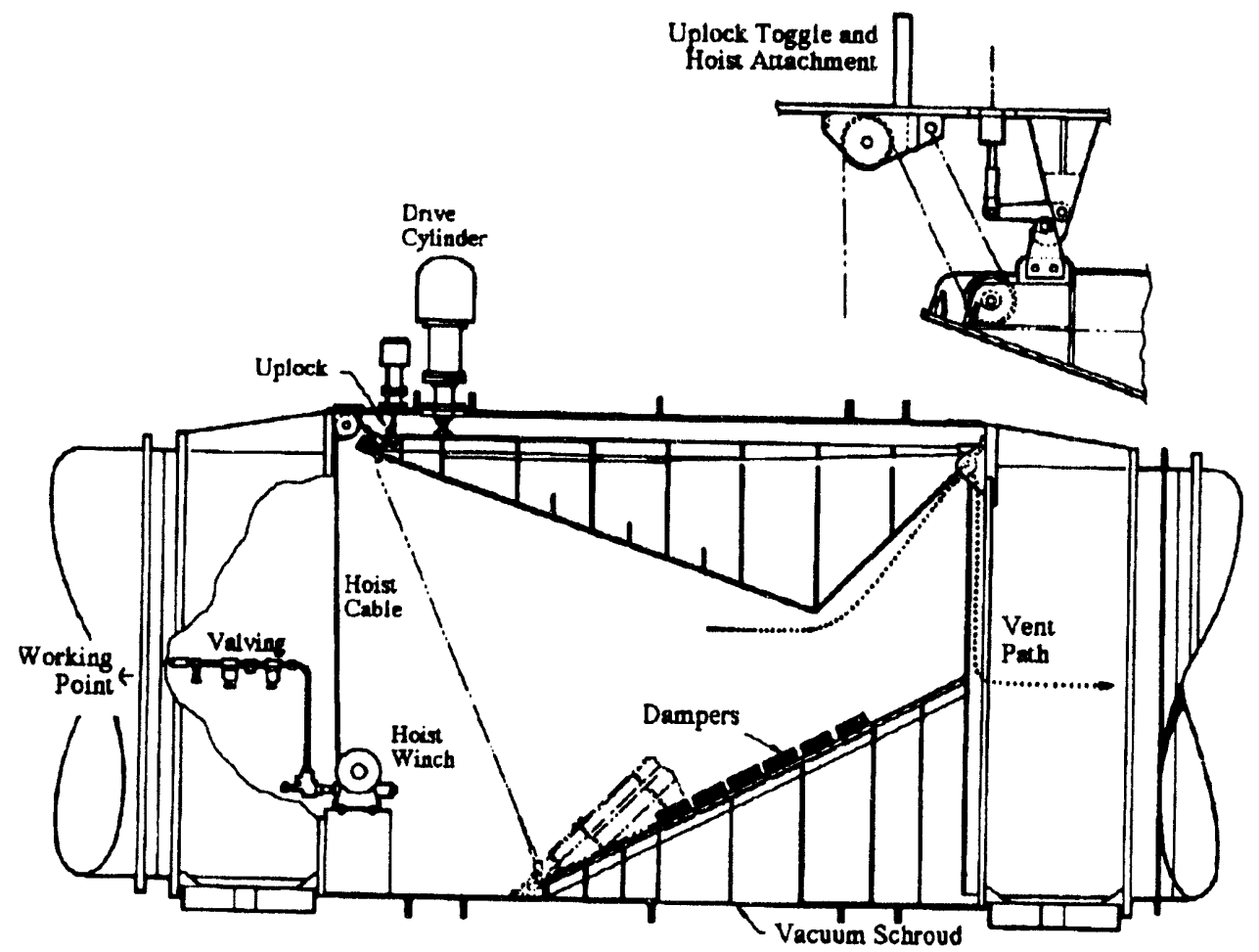

Figure A4. DBS Operation

HE Dimple Closure. The HE dimple closure was a primary barrier to highvelocity debris at early detonation times. This barrier allowed mechanisms, such as fast gates, located further up the tunnel more time to close.

The dimple pipe section, seen in Figure A5, included two separate systems:

- Standard Dimple. The standard dimple consisted of an HE charge of $\sim 18$ pounds. The purpose was to fold in the HLOS pipe at an early afterdetonation time without fracturing the pipe.

- Cutter Dimple. The cutter dimple incorporated a shaped cutting charge at the forward end of the HE charge. The purpose was to cut the 1 -inchthick steel HLOS pipe along the circumference so that a relatively light charge could open the pipe and divert early arriving energy out of the HLOS pipe. The cutter dimple could be used in conjunction with one or as many as three standard dimples. 


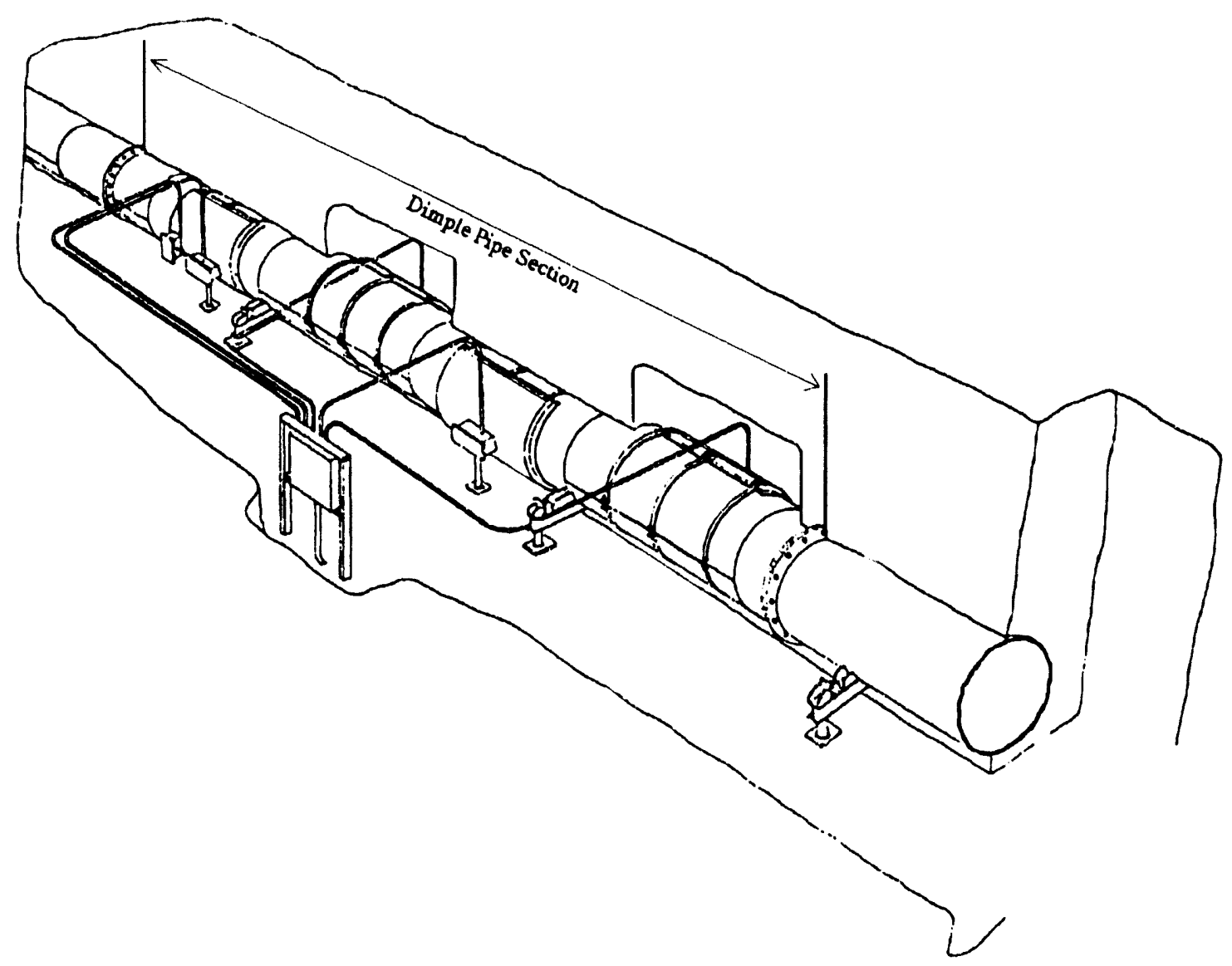

Figure A5. High-Explosive Dimple Closure

Sample Recovery Canister. The SRC unit was a thick-walled pressure vessel in which an experiment was housed. The SRC provided close-in experiment protection while permitting post-shot recovery. An aperture of either 4 or 8 inches was at the forward end for an unobstructed view of the nuclear device. The experiment to be protected was placed in a thick-walled section at the rear of the canister. The closed (but not gas tight) canister that was nearly solid was sufficiently strong to withstand ground-shock compression and to permit recovery and experiment retrieval.

- The 4-in. SRC was 38 in. long, 9 in. in diameter, and weighed $480 \mathrm{lbs}$;

- The 8-in. SRC was $60 \mathrm{in}$. long, $17 \mathrm{in}$. in diameter, and weighed $2200 \mathrm{lbs}$.

Closure was accomplished by pinching the SRC closed at the forward end with the use of a tapered explosive collar. The collar had a tamper that directed the explosive energy against the canister wall by means of two line-wave generators. Two detonators ignited the high explosive that propagated the detonation to the line-wave generators, which in turn ignited two pounds of flexible explosive, uniformly and simultaneously, placed around the circumference of the unit. This explosive charge was sandwiched be- 
tween a lead tamper and the tapered outer wall of the tubing to be pinched off. Approximately $80 \mathrm{~ms}$ after detonator ignition, wall motion began, and the shock front propagated down the tapered wall, increasing the wall thickness with enough force to implode, constrict, and fuse together the driven wall portions to form a solid wall closure across the passageway.

Complete closure was achieved within 180 and $280 \mathrm{~ms}$ for the 4 -in. and 8 -in. SRCs, respectively. The detonators were extremely reliable; all installed and tested SRCs functioned properly. The SRC was used in CYPRESS (2/12/69) and in other events. Figure A6 shows a cross-section of an SRC.

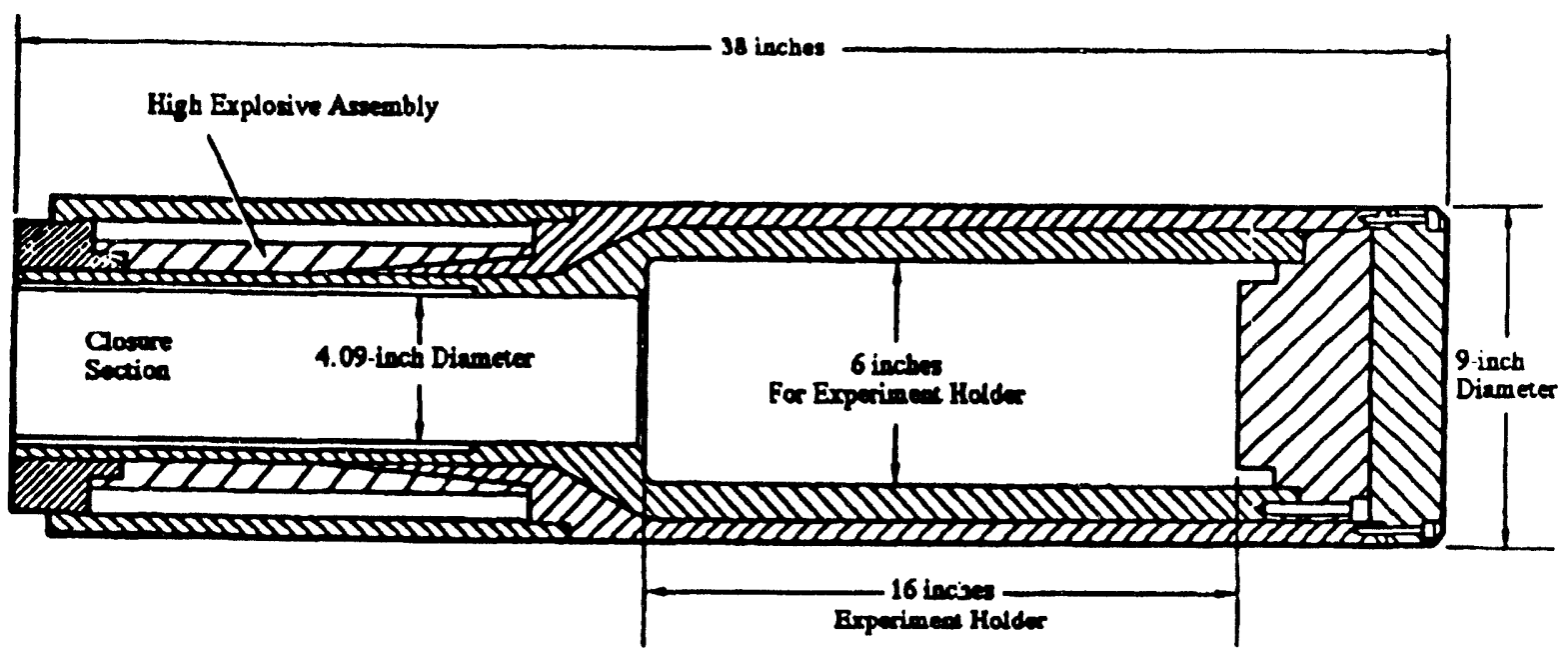

Figure A6. Cross-Section of a Sample Recovery Canister

Auxiliary Closure (28.5 in. $x$ 36.6 in.). Two important new features in the design of this closure system and in the 60-in. auxiliary closure described below were the release and driving system and the stopping/latch system. The opening to be closed was a rectangular cross-section measuring 28.5 in. $x 36.6$ in. The overall measurements of the closure were 86 in. high, 152 in. wide, and 62 in. long. Each of the two aluminum gates was 12 in. thick. The complete assembly, including the massive housing, weighed 75,000 lbs.

Two of these closures, seen in Figure A7, were used on project DIDO QUEEN (6/5/73). The nitrogen gas reservoirs were pressurized to $16,000 \mathrm{psi}$. The closure's main function was to obscure the LOS pipe leading to the experiment station, thus shielding the experiments within the station from pipe energy, blast debris, and stemming material flow. Both closures were destroyed during the event, but prior test results showed obscuration at 7.1 $\mathrm{ms}$ and full closure at $12.8 \mathrm{~ms}$. 


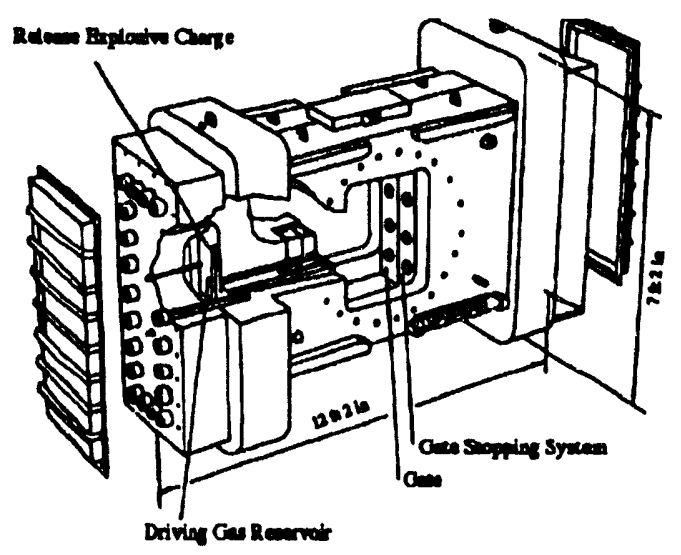

Figure A7. Auxiliary Closure (28.5-inch)

Auxiliary Closure (60-Inch). This auxiliary closure was developed to close across a 60-inch-diameter circular pipe opening. The unit consisted of two aluminum gates. Each gate was 68 in. x 68 in. x 12 in. and weighed 4000 lbs. The two gates were enclosed in a massive steel housing. Pressure vessels were ruptured by an explosive cutting charge that drove the gates across the closure aperture from opposite sides, obscured the HLOS pipe within $16 \mathrm{~ms}$, and accomplished full closure in $32 \mathrm{~ms}$.

The housing provided guidance for the gates and strength for the pneumatic driving system and supported the stopping/latch system. The housing was surrounded by a high-strength concrete plug that formed a composite structure (with the gates in the closed position) that could resist an applied pressure to $\sim 14,000 \mathrm{psi}$. The assembled closure was $20 \mathrm{ft}$. long, $10 \mathrm{ft}$. high, $\sim 3 \mathrm{ft}$. thick and weighed $180,000 \mathrm{lbs}$.

The release and driving system consisted of high-pressure reservoirs positioned between the gate and end cover of the housing. The 600-grainper-foot linear-shaped explosive cutting charge was placed around the reservoir in the vertical plane, perpendicular to the axis of the long axis of the door and housing. Before closing, the high-pressure, nitrogen-filled reservoirs were pressurized to $\sim 16,000 \mathrm{psi}$. Closing was initiated by igniting the cutting charge, which severed the reservoir and allowed the gas to expand and push against almost the entire end area of the gate. This force accelerated the gate, driving it across the opening. Figure A8 shows the operational design of the closure. 


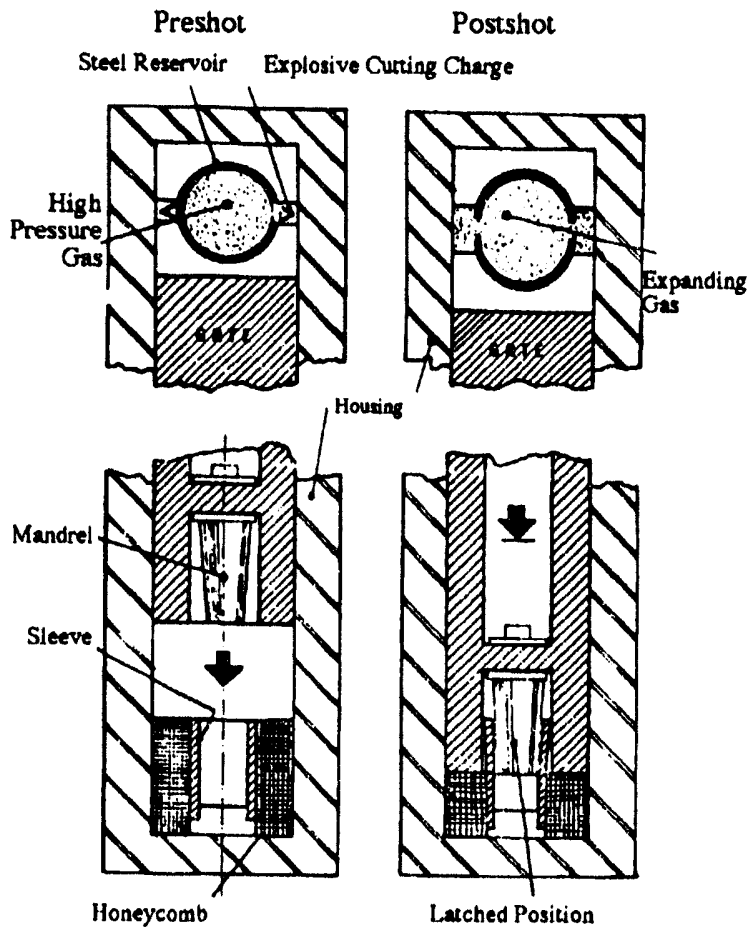

Figure A8. Pneumatic Driving Mechanism and Mandrel Latch Concept of the 60-inch Auxiliary Closure

The stopping/latch system had to decelerate, stop, and firmly hold in place the rapidly moving heavy gate within a short distance. A pad of $6000 \mathrm{psi}$ crush strength aluminum honeycomb served to absorb, by crushing, most of the kinetic energy of the gate. A set of four latch systems absorbed the remaining gate energy and latched the gate firmly in the closed position. Each latch system was comprised of a tapered steel mandrel that was mounted in the leading edge of the gate and a thick-walled steel sleeve that was mounted on the end of the closure housing (surrounded by the aluminum honeycomb pad). As the gate reached the closed position, the tapered mandrels engaged the steel sleeves, forcing them to expand, and thereby created the large forces that opposed gate motion and caused additional energy dissipation. The large radial force between the mandrel and the steel sleeve, coupled with high steel-on-steel coefficient of friction, created the latch capability.

The development model of this closure mechanism was tested at Sandia in November 1971. SNL then designed, built, and installed these 60-in. auxiliary closure systems for the MISTY NORTH (5/2/72) and the DIAMOND SCULL (7/20/72) events. 


\title{
Appendix B: \\ Characteristics of Large Gas-Actuated Closures
}

\author{
(Excerpted from the work ${ }^{B 1}$ of M. D. Bennett and J. C. Weydert: \\ Dynamics of Gas-Actuated Pipe Closures,)
}

To describe the general behavior of large, quick-acting pipe closures, the 62 inch lightweight modified auxiliary closure (MAC), with a 6:-inch stroke, was selected as a representative standard. Unless otherwise noted, the reservoir contains nitrogen gas with an initial pressure of $1000 \mathrm{~atm}$ at a temperature of $297^{\circ} \mathrm{K}$.

The displacement-time history of the gas-driven gate, without the added effect of the pyrotechnic energy, shows that at a pressure of $10 \mathrm{~atm}$, the ideal-gas and real-gas models exhibit no discernible difference. At $100 \mathrm{~atm}$, the gate-closing time in the real-gas case is increased a few percent relative to the elementary ideal-gas model. At $1000 \mathrm{~atm}$, significant variations become apparent. The effect of the strong detrimental intermolecular forces that accompany densely packed gases is even more evident in the gate velocity histories. The real-gas model yields little more than one-half the velocity obtained with the idealized prediction. Imperfect gas characteristics obviously play a dominant role at high-operating pressures, and they must be taken into account for accurate performance estimates.

The effectiveness of two different working fluids was compared:

- Helium: a monatomic gas

- Nitrogen: a diatomic gas.

At pressures below a few hundred atmospheres, nitrogen produces the quicker gate-closing time. At the lower pressures where molecular interactions are insignificant, particular closed-form analytical solutions duly predict that the gate actuation time decreases when the molecular degrees of freedom are increased. ${ }^{\mathrm{B} 2}$ Hence, nitrogen supplies more energy to the gate than does helium when the working fluids behave as thermally perfect gases. At the higher pressures, where molecular spacing becomes important, the relatively weak intermolecular forces that arise with the elemental monatomic gas cause less loss in performance than in the case of the more complex diatomic gas, nitrogen. Consequently, the trend is reversed with dense gases, and helium delivers more energy in that circumstance.

The reservoir capacity effect shows that although the gate-closing time continues to decrease as the reservoir volume increases, a minimum eventually occurs if the reservoir attains infinite size. In this academic case of unlimited gas supply, the pressure propelling the gate remains constant. In the absence of friction or heat transfer, the actuation time becomes $t=2 \mathrm{mx} / \mathrm{S}(\Delta \mathrm{p})$. Thus, when the back pressure is zero, the closing time at $1000 \mathrm{~atm}$ is $9.90 \mathrm{~ms}$. This amounts to $39 \%$ of the nominal value and 
establishes the limit of performance for an inert gas system. Some other source of energy would be required to reduce the actuation time further.

Because of slight irregularities in the assembled dimensions of the system's component parts, a small, unavoidable dead-air space is located between the gas reservoir and the gate end face. Since the work expended by the gas filling this void constitutes a loss, the gate actuation time is increased accordingly. With the specified manufacturing tolerances, the associated maximum possible void volume is no larger than $5.6 \%$ of the reservoir volume. The corresponding increase in gate actuation time is $\sim 11 \%$ at the 3-foot displacement position.

The force that drives the gate can be increased slightly by enlarging the working area over which the reservoir gas acts. Since the gas then undergoes a large expansion at any given displacement position, the gate receives proportionately more energy. The response time is reduced $\sim 1 \%$ if the crosssectional area is enlarged $10 \%$, provided the gate mass is maintained constant. If mass is altered, the corresponding change in actuation time can be estimated with the formula derived previously.

Numerical Solution of the Gate Motion Equation. Unsteady flow effects often accompany the rapid transfer of gas from a pressurized vessel. The lack of uniformity in the chamber is brought about by the propagation of compression and expansion waves, particularly in long channels. Since conditions in these wave-dominated discharges depend on position as well as time, recourse must be made to the more complete gas-dynamic equations to determine the state of the gas. ${ }^{\mathrm{B} 3}$ With the present arrangement, however, the gate inertia restricts the reservoir flow so that the characteristic particle speed at any station remains considerably less than the local sound speed; in this case, near-uniform conditions prevail. Consequently, average time-varying quantities adequately define the state variables. Further, the gas flow path in the gate housing is short in effect and the reservoir has a proportionally large aperture. The system is therefore taken to be characterized as a quasi-steady, uniform, frictionless, compressible flow.

The reservoir gas initially is densely packed $(\simeq 1000$ atm at room temperature), which results in large intermolecular forces. Since the elementary thermally perfect gas model neglects these interactions, a non-ideal equation of state is required. In the 1979 investigation of Bennett and Curry, B2 a set of ordinary differential equations was developed that describes the onedimensional translational motion of the gate. Numerical solutions were obtained for both ideal gases and real gases.

With nitrogen functioning as an ideal gas, the error in the predicted gate response time amounted to $37 \%$ at 1000 -atm pressure. The then-available real-gas equation of state had a restricted range of applicability, and extrapolation was necessary. Although the response time error was reduced to $10 \%$ with the real-gas model, the error in the gate terminal speed was 
excessive; ordinarily, the error in the gate terminal speed is larger than the corresponding time error. To improve the accuracy of the predictions and to assess the performance of different kinds of working fluids, comprehensive state equations were needed.

As part of the work at the Tritium Research Center at Sandia National Laboratories in Livermore, highly accurate equations of state were assembled for mixtures of hydrogen isotopes and the inevitable helium decay products. B4 These equations were compiled, along with the equations for several other gases often encountered in gas-dynamic applications, into a library of computer routines. ${ }^{B 5}$ The tables extend up to several thousand atmospheres of pressure, with the temperature ranging from the cryogenic realm to $400^{\circ} \mathrm{K}$. The tables also define the gas properties for the gate motion analysis.

A generalized internal-flow computer $\operatorname{code}^{\mathrm{B} 6}$ was adapted to the problem of modeling gate motion with an arbitrary equation of state. The code describes a gas in networks of pressure vessels of either constant or variable volume, with or without heat transfer or flow losses in the interconnecting lines. It is used here with a piston (gate) in the circuit and with the gas nitrogen or helium. The thermal characteristics are those specified in References B5 and B7. The coefficient of sliding friction $f$ for the gate was taken to be constant: $f=0.2$. The gate back-face pressure was also maintained constant, fixed at the initial value which was a few micrometers of mercury.

The gas reservoir is equipped with a linear-shaped charge that serves to release the stored gas by cutting a major section from the vessel wall. The pyrotechnic energy, which amounts to $7.58 \mathrm{~kJ} / \mathrm{cm}$, with a total that exceeds the energy in the reservoir gas is of necessity somewhat greater than that required to cut through the wall. A significant part of the surplus energy is recovered in the form of heat, which helps drive the gate; a small part of the energy is also recovered by momentum exchange between the gate face and the copper sheath that houses the explosive charge. Almost two thirds of the shaped-charge energy goes into the sheath. The rest of the pyrotechnic energy remains invested in the $\mathrm{HE}$ detonation products.

The hot gases, which by weight amount to no more than $3 \%$ of the reservoir gas, supply most of the recovered energy. (Approximately one fourth of recovered heat is received from the copper sheath. It represents up to one sixth of the sheath's kinetic energy. ${ }^{B 8}$ ) The gases are presumed to mix instantaneously without loss with the working fluid. The model also assumes that thermodynamic equilibrium prevails in the composite mixture and that the state equation endures unaltered.

The surplus energy from the shaped-charge detonation serves to enhance initial conditions for the numerical solutions. The pressure and temperature of the gas mixture in the reservoir are immediately elevated, and the 
gate receives a small initial velocity from the impact of a portion of the copper sheath.

In summarizing the results of the numerical calculations, the errors in the time predictions range from $-3.3 \%$ to $+5.3 \%$. There is no apparent correlation of the error with the variations in reservoir gas pressure or reservoir size, or with the changes in gate dimensions. With assumed error bands applied in a cumulative manner to the 12 independent quantities that regulate the numerical model, the gate response time would vary a maximum of $\pm 1.2 \%$. Unknown forces account for the balance of the observed variations in the system errors.

The kinetic energy imparted to the gate, as evidenced by one-dimensional translational motion, along with the usable energy in the reservoir gas, shows that the gate receives from $19 \%$ to $56 \%$ more energy than is available in the stored fluid, and that about one half of the total energy (pyrotechnic and reservoir gas energies) is delivered to the gate.

Conclusions. From the numerical analysis of a model based on working fluids that consist of an equilibrium mixture of the reservoir inert gas and the detonation products released by the shaped charge, the maximum error in the computed gate actuation time for nitrogen-driven systems is found to be $5 \%$. The model predicts a crossover point when assessing the performance of different reservoir gases. In the case of supply pressures below a few hundred atmospheres, nitrogen produces the quicker gate-closing time. However, helium at $1000 \mathrm{~atm}$ results in an estimated $21 \%$ reduction in the actuation time. With helium, the relative gate response continues to improve as the pressure is further increased. 


\section{Appendix B References}

B1. M. D. Bennett and J. C. Weydert, Dynamics of Gas-Actuated Pipe Closures, SAND86-1820 (Albuquerque, NM: Sandia National Laboratories), November 1986.

B2. M. D. Bennett and W. H. Curry, Response of a Quick-Acting Valve for Underground Nuclear Blast Containment, SAND79-1864 (Albuquerque, NM: Sandia National Laboratories), Oct 1979.

B3. W. G. Vincenti and C. H. Kruger, Introduction to Physical Gas Dynamics, (New York: Wiley Co., 1965), p 194.

B4. W. T. Ashurst, Equilibrium and Transport Estimates for Hydrogen and Helium via Lennard-Jones Fluid, SAND76-8720 (Albuquerque, NM: Sandia National Laboratories), Dec 1976.

B5. G. L. Clark, Real Gas Equation-of-State Capability at Sandia Livermore, SAND78-8200 (Albuquerque, NM: Sandia National Laboratories), March 1978.

B6. G. L. Clark, A Zero-Dimensional Model of Compressible Gas Flow in Networks of Pressure Vessels, SAND83-8226 (Albuquerque, NM: Sandia National Laboratories), July 1983.

B7. R. T. Jacobsen and R. B. Steward, Thermodynamic Properties of Nitrogen Including Liquid and Vapor Phases from $63 \mathrm{~K}$ to $2000 \mathrm{~K}$ with Pressure to 10,000 Bar, J Phys Chem Reference Data, Vol. 2, No. 4, 1973.

B8. J. D. Means and R. D. Ulrich, Transient Convective Heat Transfer During and After Gas Injection into Containers, J. Heat Trans. (ASME), May 1975. 


\section{Distribution:}

1 Lawrence Livermore National

Laboratory (LLNL)

Attn: Q Clearance Recipient, L-313

PO Box 808

Livermore, CA 94550

1 Los Alamos National Laboratory

Attn: Report Librarian

PO Box 1663

Los Alamos, NM 87545

1 US Department of Energy

Nevada Operations Office

Attn: Mail \& Records

PO Box 14100

Las Vegas, NV 89114

13 Field Command, Defense Nuclear Agency (DNA)

Attn: Capt. James Arsenault, DNA/CEMS

J. W. LaComb, DNA/FCTC (10)

W. J. Summa, DNA/FCTT

Kirtland AFB

Albuquerque, NM 87115

1 Dan Patch

Pacifica Technology

11696 Sorrento Valley Road

San Diego, CA 92121

\section{$1 \quad$ MSO437 \\ 1 MS1033 \\ 1 MS1165 \\ 1 MS1158 \\ 1 MS1170 \\ 1 MS1161 \\ 2 MS1159}

1

1

1

1

1

\section{1}

\section{1}

\section{1}

1

1

1

\section{6}

MS1156

1 MS1156

6 MS1156

1 MS1156

1 MS0763

1 MS9018

5 MS0899

$1 \quad$ MS0619

10 MS0100
K. Schuler, 1562

G. E. Staller, 6111

J. E. Powell, 9300

J. D. Plimpton, 9301

M. J. Navratil, 9305

S. R. Dolce, 9308

A. J. Chabai, 9311

Attn: John Banister R. C. Bass

L. R. Hill, 9311

C. W. Smith, 9311

W. H. Barrett, 9311

F. Biggs, 9312

R. C. Shear, 9313

C. W. Cr 'k, 9322

B. C. Bedeaux, 9323

G. L. Ogle, 9323

P. L. Nelson, Jr., 9324

M. F. Aker, Jr., 9331

A. B. Church, 9332

O.L. Burchett, 9333

G. M. Ponder, 9333

D. P. Shenk, 9333

J. C. Weydert, 9333

C. R. Cherry, 9333

H. C. Walling, 9614

Central Tech. Files, 8523-2

Technical Library, 7141

Tech. Publications, 7151

Doc Proc for DOE/OSTI, 7613-2 
$r$
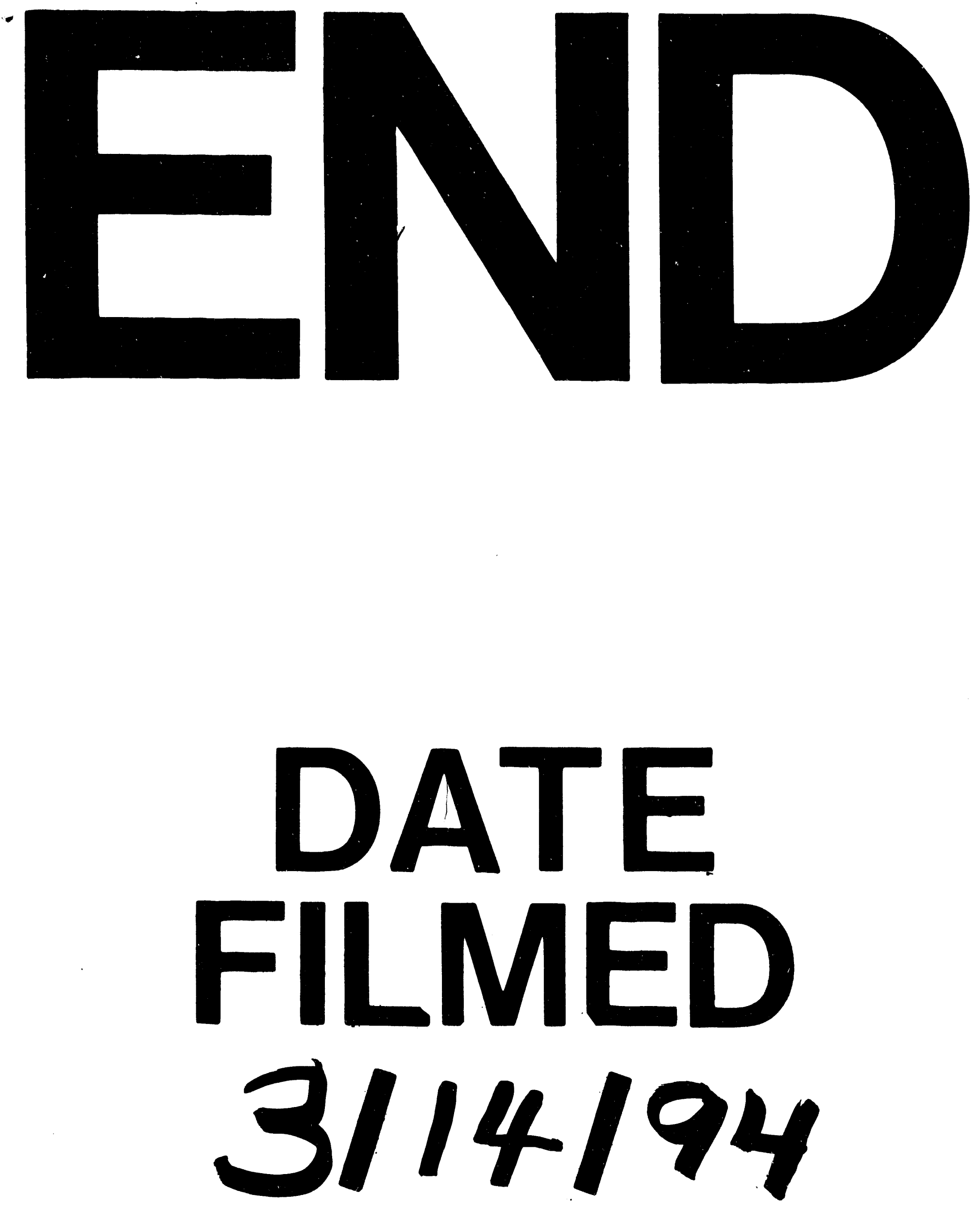

1 